February 2003 ・ NREL/TP-620-31221

\title{
Optimizing the Level of Renewable Electric R\&D Expenditures Using Real Options Analysis
}

G. Davis

Colorado School of Mines

Golden, Colorado

B. Owens

National Renewable Energy Laboratory (Currently with Platts Research \& Consulting)

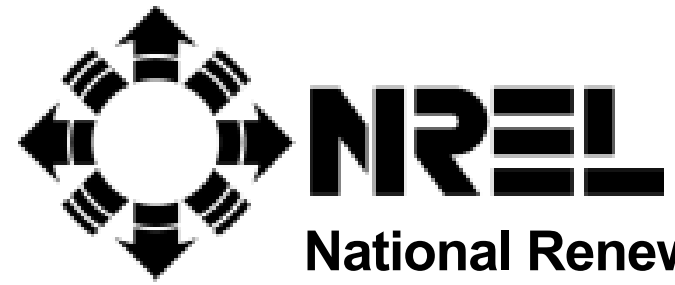

1617 Cole Boulevard Golden, Colorado 80401-3393

NREL is a U.S. Department of Energy Laboratory Operated by Midwest Research Institute $\bullet$ Battelle $\bullet$ Bechtel 
February 2003 • NREL/TP-620-31221

\section{Optimizing the Level of Renewable Electric R\&D Expenditures Using Real Options Analysis}

G. Davis

Colorado School of Mines

Golden, Colorado

B. Owens

National Renewable Energy Laboratory (Currently with Platts Research \& Consulting)

Prepared under Task No. AS65.2010

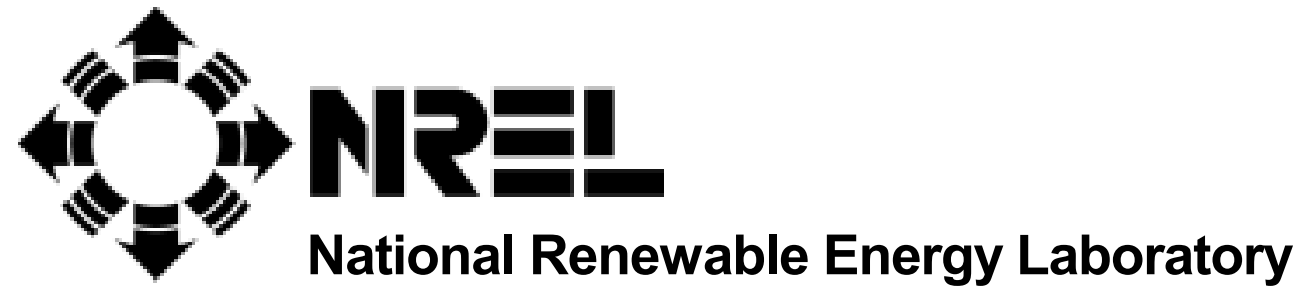

1617 Cole Boulevard

Golden, Colorado 80401-3393

NREL is a U.S. Department of Energy Laboratory

Operated by Midwest Research Institute • Battelle • Bechtel

Contract No. DE-AC36-99-G010337 


\section{NOTICE}

This report was prepared as an account of work sponsored by an agency of the United States government. Neither the United States government nor any agency thereof, nor any of their employees, makes any warranty, express or implied, or assumes any legal liability or responsibility for the accuracy, completeness, or usefulness of any information, apparatus, product, or process disclosed, or represents that its use would not infringe privately owned rights. Reference herein to any specific commercial product, process, or service by trade name, trademark, manufacturer, or otherwise does not necessarily constitute or imply its endorsement, recommendation, or favoring by the United States government or any agency thereof. The views and opinions of authors expressed herein do not necessarily state or reflect those of the United States government or any agency thereof.

Available electronically at http://www.osti.gov/bridge

Available for a processing fee to U.S. Department of Energy and its contractors, in paper, from:

U.S. Department of Energy

Office of Scientific and Technical Information

P.O. Box 62

Oak Ridge, TN 37831-0062

phone: 865.576 .8401

fax: 865.576.5728

email: reports@adonis.osti.gov

Available for sale to the public, in paper, from:

U.S. Department of Commerce

National Technical Information Service

5285 Port Royal Road

Springfield, VA 22161

phone: 800.553.6847

fax: 703.605.6900

email: orders@ntis.fedworld.gov

online ordering: http://www.ntis.gov/ordering.htm 


\section{Acknowledgments}

The views expressed in this paper are those of the authors and do not necessarily reflect those of the Colorado School of Mines (CSM) nor Platts Research \& Consulting (PRC). The authors wish to thank Dr. Steven Ott and Dr. Shimon Awerbuch for their valuable comments. They also thank Dr. Junping Wang from the Colorado School of Mines Department of Mathematical and Computer Sciences for assistance with the numerical analysis used in this paper. Finally, the authors thank the National Renewable Energy Laboratory, which provided initial funding for this research. Graham Davis is associate professor of Economics and Business at the Colorado School of Mines and can be reached via e-mail at gdavis@mines.edu. Brandon Owens (formerly of the National Renewable Energy Laboratory) is power market consultant at Platts Research \& Consulting (PRC) and can be reached via e-mail at brandon_owens@platts.com. 


\section{TABLE OF CONTENTS}

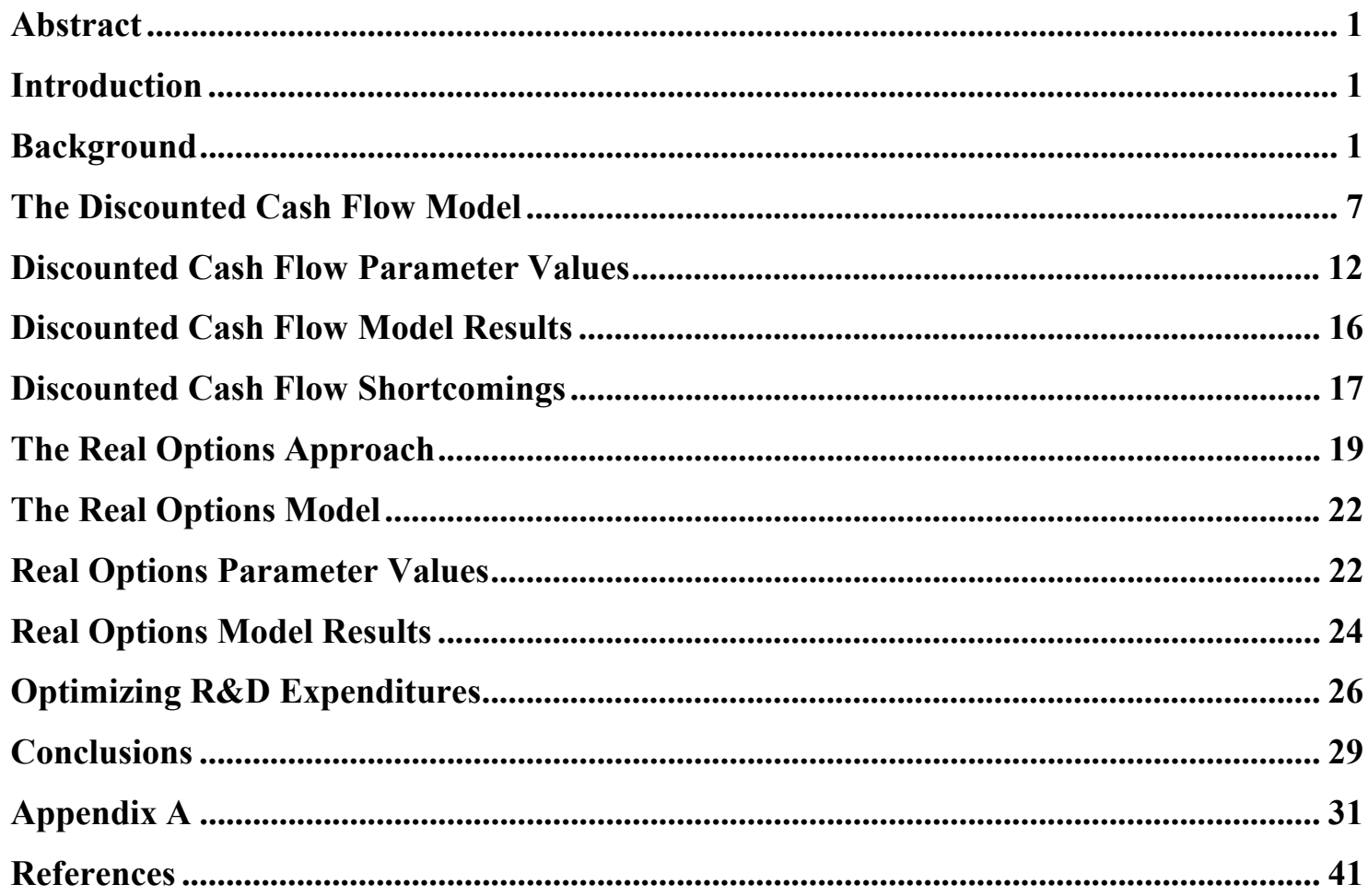




\section{Abstract}

One of the primary objectives of the United States' federal non-hydro renewable electric R\&D program is to promote the development of technologies that have the potential to provide consumers with stable and secure energy supplies. In order to quantify the benefits provided by continued federal renewable electric $\mathrm{R} \& \mathrm{D}$, this paper uses "real option" pricing techniques to estimate the value of renewable electric technologies in the face of uncertain fossil fuel prices. Within the real options analysis framework, the current value of expected future supply from renewable electric technologies, net of federal $R \& D$ expenditures, is estimated to be $\$ 30.6$ billion. Of this value, $86 \%$ can be attributed to past federal R\&D efforts, and $14 \%$ can be attributed to future federal R\&D efforts, assuming continued federal R\&D funding at $\$ 300$ million/yr. In addition, real options analysis shows that the value of renewable electric technologies increases as current and future $R \& D$ funding levels increase. This indicates that the current level of federal renewable electric R\&D funding is sub-optimal low.

\section{Introduction}

The purpose of this paper is to quantify the value of the United States' (U.S.) federal non-hydro renewable electric $R \& D$ program. In order to quantify the value of renewable electric $R \& D$, we first examine the market value of these technologies from the traditional discounted cash flow (DCF) perspective, a valuation perspective that does not consider optimal deployment timing or insurance value. We then examine the market value of renewable electric technologies using a "real options" analysis framework, which draws upon insights from financial markets to value a broader range of benefits including insurance value.

\section{Background}

In 1973, several Arab nations, angered at U.S. support of Israel in the 1973 Arab-Israeli War, instituted an oil embargo against the U.S. and Holland. The Arab oil embargo came at a time of declining domestic crude petroleum production, rising demand, and increasing imports. The embargo was also accompanied by decreased production from the Organization of Petroleum Exporting Countries (OPEC). Because non-OPEC nations had minimal excess production capacity, the embargo created petroleum shortages and price increases. World crude petroleum 
prices more than doubled in a six-month period (Figure 1) and annual U.S. consumer petroleum expenditures nearly doubled, rising from $\$ 56$ billion to $\$ 97$ billion dollars (EIA 2000a). The U.S. government's renewable electric (RE) R\&D program was initiated in 1974 to promote the development of technologies that have the potential to provide consumers with stable and secure renewable electric supplies in a high fossil fuel-price environment. Reducing U.S. vulnerability to energy supply disruptions is still one of the primary missions of the RE R\&D program, which has received increased attention in light of the September 11, 2001, terrorist attacks on New York and Washington, D.C.

Figure 1: F.O.B. Cost of U.S. Petroleum Imports*

$(10 / 73-2 / 74)$

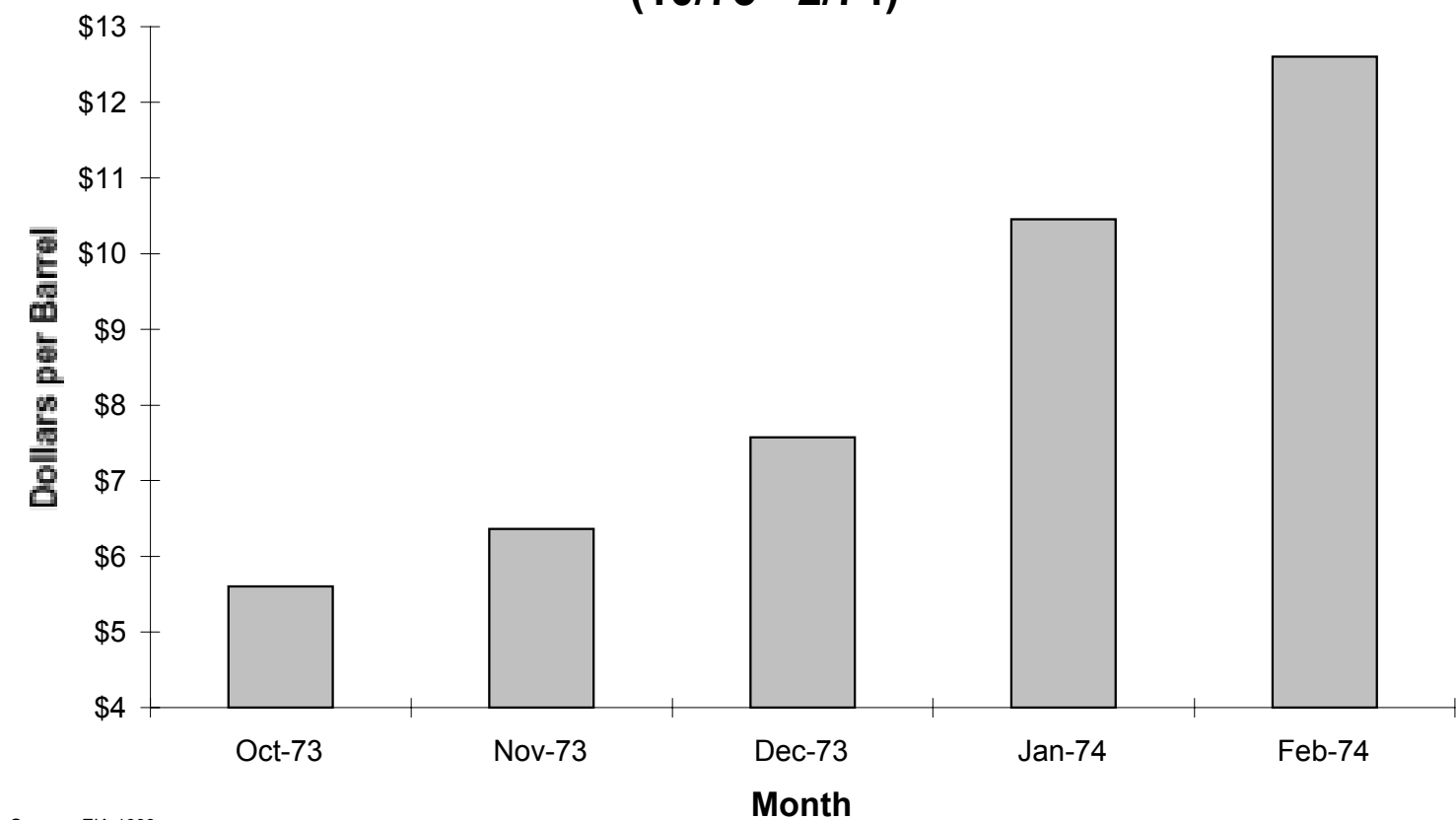

F.O.B. literally means "Free on Board." It denotes a transaction

Between fiscal year (FY) 1974 and FY 2000, nearly \$13.5 billion (1992) dollars were spent on the U.S. federal RE R\&D program (Figure 2). During this time, approximately $90 \%$ of program dollars were distributed among six key RE technologies: concentrating solar power (CSP), photovoltaics (PV), geothermal energy, electric storage systems, wind, and bioenergy (Figure 3). 
Figure 2: Renewable Energy R\&D Program Funding

(FY 1974 - FY 2000)

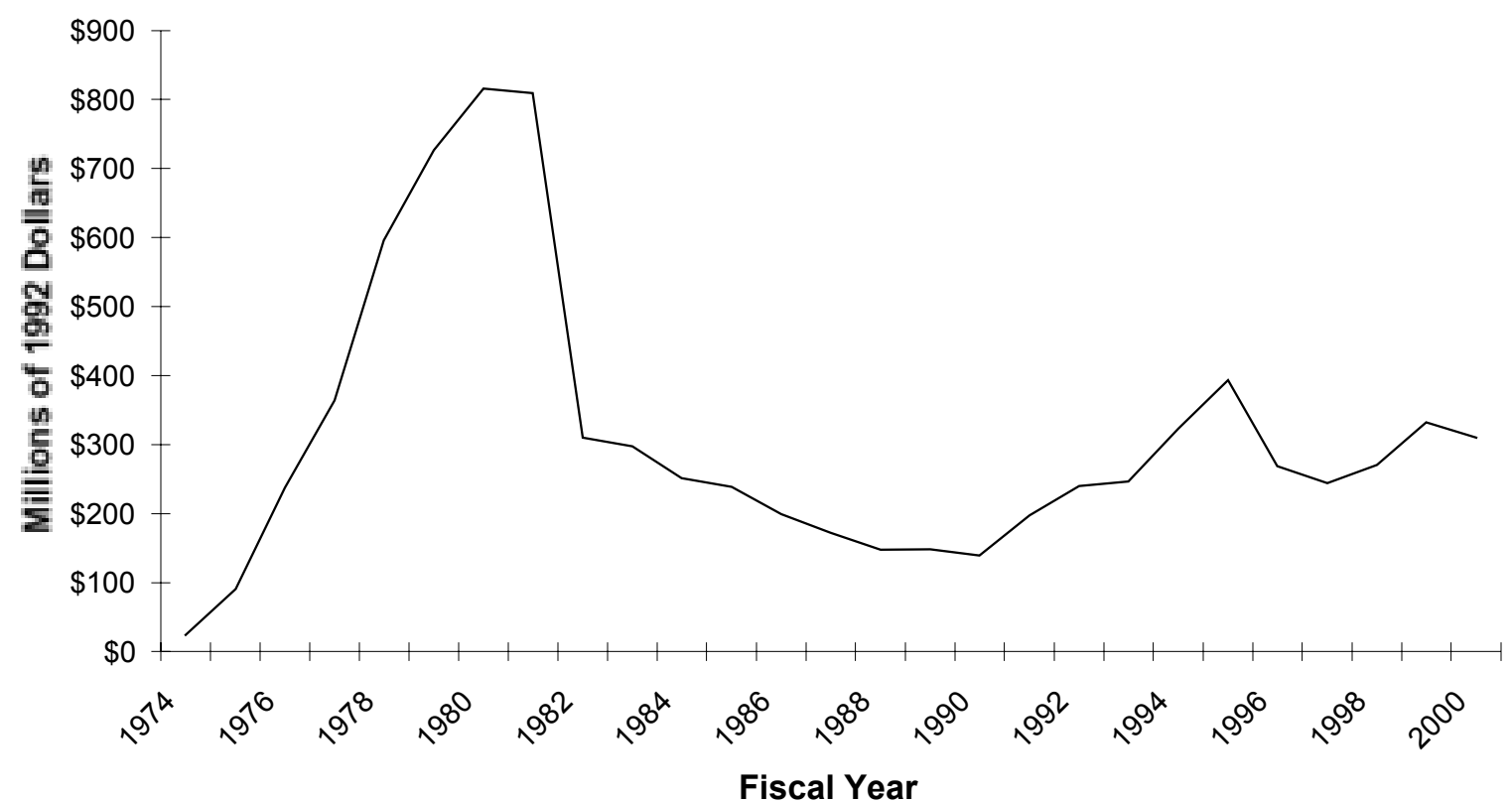

Source: FY73-FY90 Sisson Congressional Research Service article; FY90-FY00 Presidential budget requests and DOE budget highlight documents.

Figure 3: Renewable Energy R\&D Program Funding Distribution (FY 1974 - FY 2000)

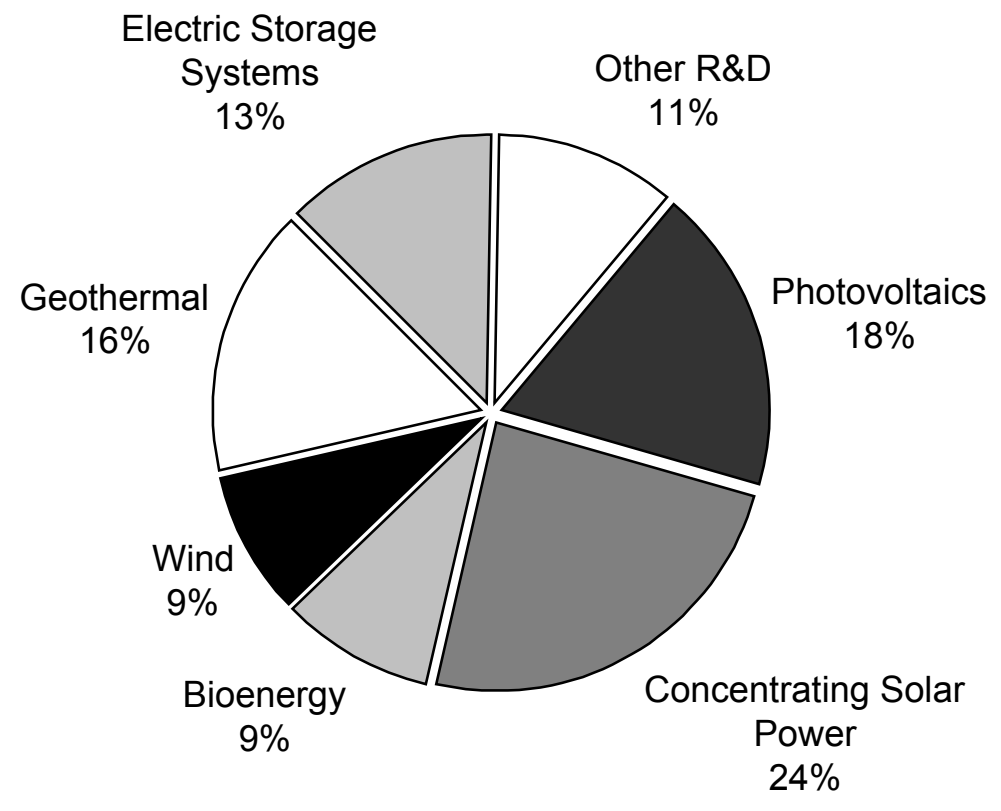

Source: FY73-FY90 Sisson Congressional Research Service; FY90-FY00 Presidential budget requests and DOE budget highlight documents. 
In the nearly three decades since its inception, the federal RE R\&D program has achieved numerous technical successes. For example, in 1980, wind energy costs were about 45 cents per kilowatthour ( $\phi / \mathrm{kWh}$ ) (McVeigh et al. 2000). Today, large, utility-scale wind turbines are being installed that can produce electricity for 4 to $6 \phi / \mathrm{kWh}$, depending on the wind resource and the financial structure. This cost is actually lower than the projections made by technology specialists in 1980. Photovoltaic (PV) energy is another technology success story. Thin-film PV modules have recently achieved conversion efficiencies of greater than 12\% (EERE 2000). Conversion efficiency improvements have helped reduce the cost of electricity from PV systems from more than $\$ 1 / \mathrm{kWh}$ in 1980 to just more than $20 \propto / \mathrm{kWh}$ today (McVeigh et al. 2000). In fact, the costs of all RE technologies under development have decreased dramatically since the federal R\&D program's inception, and recent studies project continuing declines in costs in the coming decades due to continued technical research (PCAST 1997).

RE technologies have also experienced market success in the United States. Wind technologies in particular have demonstrated impressive recent market growth. Driven primarily by federal tax incentives that make wind energy competitive with conventional fossil fuel-fired sources, U.S. wind capacity grew from slightly more than 1,500 megawatts (MW) in 1998 to 4,261 MW by the end of 2001 (AWEA 2002, EIA 2000c) Still, in the context of total U.S. electric capacity, RE technologies have yet to emerge as dominant players. In 2000, non-hydro RE technologies accounted for only 4\% of installed U.S. electric capacity (EIA 2001) (Figure 4).

However, an examination of energy market conditions reveals that the lack of widespread adoption of RE technologies has more to do with changes outside the R\&D program than with the performance of RE technologies (McVeigh et al. 2000). An increasingly competitive world petroleum market has led to a decline and stabilization in the price of petroleum to such an extent that by 1998 the real price of petroleum was the lowest since prior to the 1973 oil embargo (Figure 5). Changes in the natural gas industry in the 1980s and 1990s have led to an increasingly competitive market with associated natural gas price declines. And generation technology advances have brought the costs of fossil fuel-fired generation down to 3-4 $\varnothing / \mathrm{kWh}$. The net result of all of this is that the cost of generation from conventional fossil fuel sources declined in tandem with, although at a less rapid rate than, the cost of electricity generation from RE technologies. 
Figure 4: 2000 U.S. Electric Capacity by Source

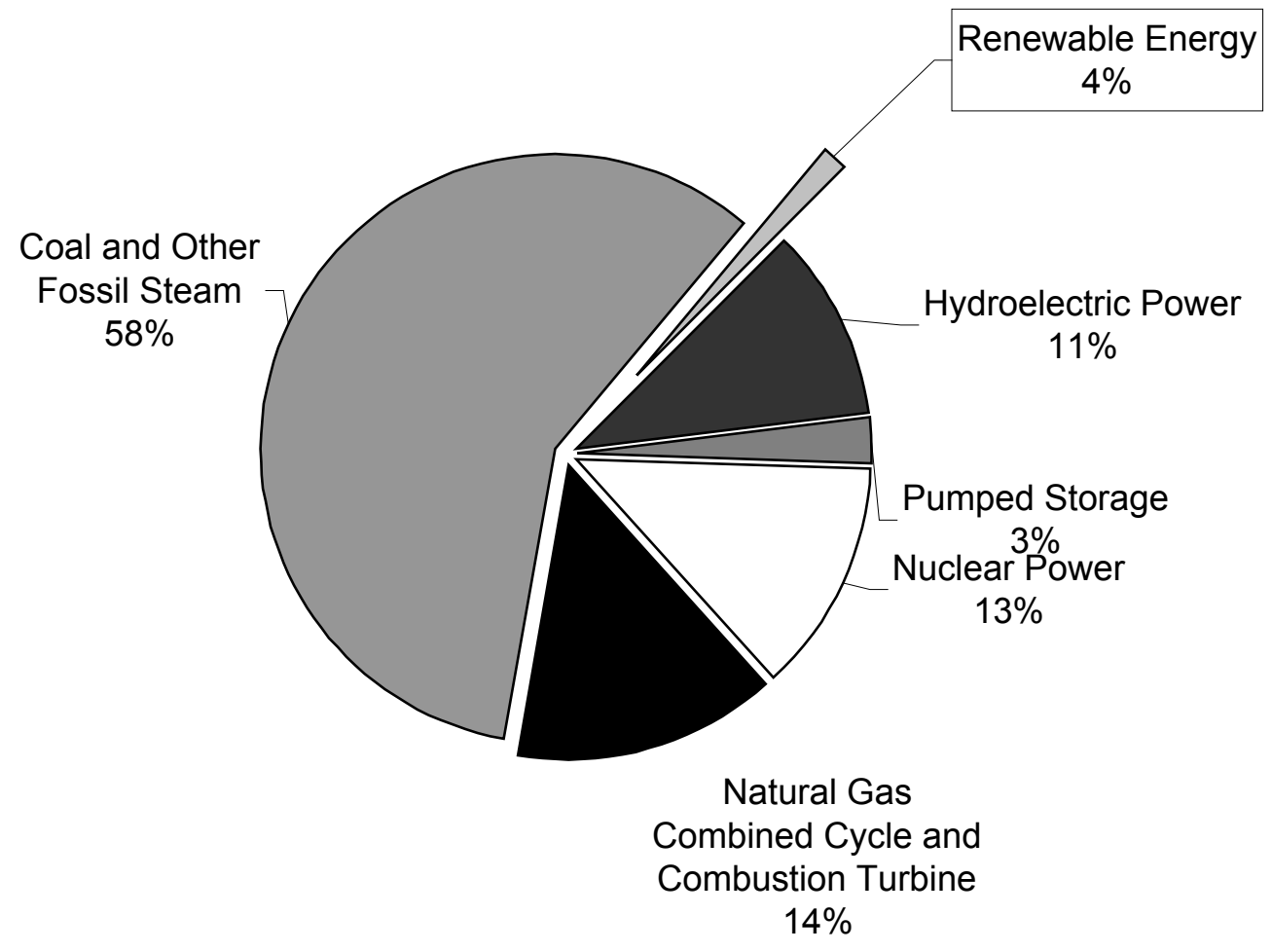

Figure 5: Crude Oil Refiner Acquisition Costs

(1974 - 1999)

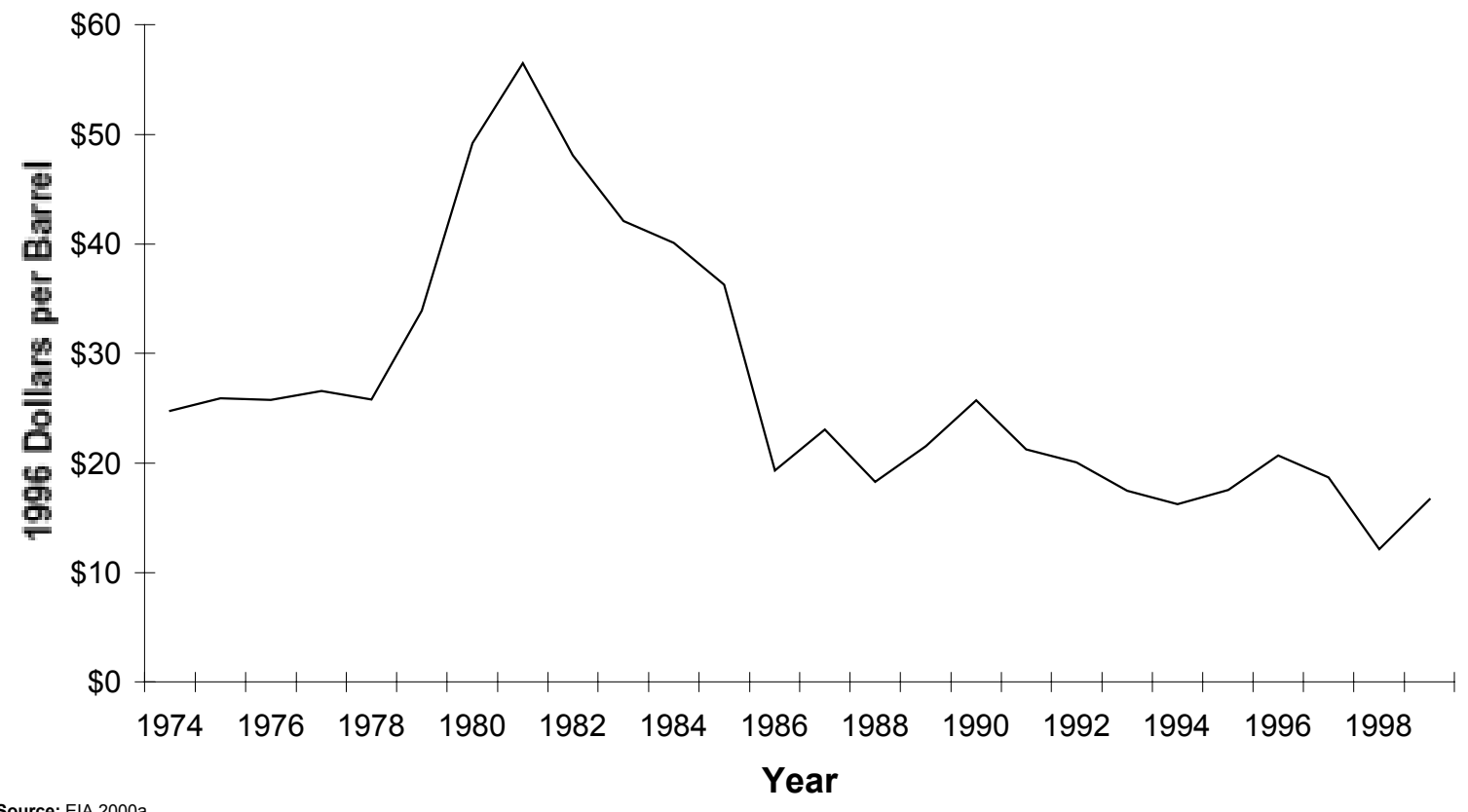


By the 1990s, the limited amount of U.S. RE capacity led some analysts to question the value of federal RE R\&D investments (for example, see Taylor 1999; Management Information Services 1998; Bradley 1997; Cohen and Noll 1991; and Ball and Tabors 1990). Skeptics began asking why the U.S. is continuing to invest millions of dollars annually in high-cost RE technologies in an era of low-cost fossil fuels. This question has recently surfaced again, this time in the context of lower electricity prices and a glut of power capacity (see Taylor and Van Doren 2002). Of course, this question reflects a basic lack of understanding of the mission of the federal RE R\&D program, which is to serve as an insurance policy that ensures domestic energy security. ${ }^{1,2}$ Nevertheless, these skeptical examinations of the federal RE R\&D program are important because they highlight the need for analysis that quantifies the value of the program. In this article, we attempt to determine the value of RE R\&D from a narrowly defined economic perspective without introducing benefits that are external to the electricity market. It is our view that if RE R\&D provides a favorable return on a narrowly defined market basis, then the need to introduce environmental and auxiliary economics benefits is diminished to the extent that these benefits will only serve to make an already favorable investment even more attractive.

We start by examining the value of RE technologies from the traditional DCF perspective, a perspective that does not consider optimal deployment timing or insurance value. We then value $\mathrm{RE}$ technologies using a real options analysis framework. Real options draws upon insights from financial markets in order to value a broader range of $\mathrm{RE}$ benefits including insurance value.

After we develop the real options model and present the results, we use the model to determine the optimal level of annual federal RE R\&D expenditures. We stress however, that the usefulness of this exercise lies in the insights provided by the real options model, not in our final annual investment recommendation. We conclude the paper by discussing our results.

\footnotetext{
${ }^{1}$ Characterizing the RE R\&D program as an insurance policy is a reasonable, but not perfect, analogy. In this case, an investment is being made to reduce the potential cost of unfavorable future outcomes. That is why one takes out insurance, as a hedge against such outcomes. When one pays an insurance premium, the policy is guaranteed to pay off if the unfavorable outcome occurs. However, with $R \& D$ expenditures there is no guarantee that the investment will payoff, since the outcome of $R \& D$ activities is uncertain.

${ }_{2}^{2}$ The insurance value of all energy R\&D was recently estimated by Schock et al. (1999) using a probabilistic framework. They estimated that the national value of energy $R \& D$ as an insurance investment to reduce the cost of the risks of climate change, oil price shocks, urban air pollution, and energy disruptions is greater than $\$ 12$ billion/year.
} 


\section{The Discounted Cash Flow Model}

The most commonly used investment valuation framework is DCF analysis. Within this framework, future benefits in terms of cash flows are estimated, usually on an annual basis, and then these cash flows are discounted at a risk-adjusted rate so that they are expressed in presentvalue dollars. Initial investment costs are then subtracted from the present value of future cash flows to yield the investment's Net Present Value (NPV). Within this framework, the investment decision rule is simple: if NPV $>0$, the investment is economic and decision makers are advised to proceed; if NPV $<0$, the investment is uneconomic and should be abandoned.

Thus, in order to determine the NPV of RE technologies within the DCF framework, we need first to estimate future technology-generated cash flows. This is a challenging task because it requires the development of an energy market model and assumptions about the rate of RE technology adoption. Although difficult, we believe it is important to undertake this exercise here because of the valuable insights that can be gained through the economic modeling process. However, as we proceed, it is important to remember that the usefulness of this exercise lies more in the insights provided by the model than in the specific numerical values obtained.

In order to estimate future cash flows generated by RE technologies, we must first create a simplified model of the U.S. electricity market. ${ }^{3}$ Positive cash flows, in the form of consumer cost savings, will arise when RE technologies are installed and provide electricity to consumers at a cost lower than that of traditional nonrenewable electric (NRE) technologies. A combination of RE R\&D success and fossil fuel-price increases will create an environment in which RE technologies are adopted in the marketplace and become the lowest cost suppliers of electricity.

The consumer cost savings generated by RE technologies in any given year can be calculated as the difference between supplying incremental demand at the expected price of NRE electricity, and that of supplying that market segment with the best available RE electricity generation technology (Figure 6). ${ }^{4}$ In this analysis, we abstract from the daily and seasonal trends in

\footnotetext{
${ }^{3}$ Since most of the technologies under development within the RE R\&D program are electricity generation technologies, our model will focus on the electricity market.

${ }^{4}$ There may be benefits or costs of an RE program that accrue to energy wholesalers and retailers. We assume these effects offset, such that we only need to focus on the benefits to the end users who ultimately consume the power.
} 
wholesale power prices and use the levelized-cost-of-electricity (LCOE) as a proxy for the expected retail electricity price, assuming that consumers pay only the marginal cost of generation from new electricity sources. ${ }^{5} \mathrm{LCOE}$ is the average cost of production per $\mathrm{kWh}$ over the technology investment life. ${ }^{6}$ In Figure 6, we denote RE electricity with the subscript $R$, and NRE electricity with the subscript $F$ (for fossil fuel). In Figure 6, $S_{F}$ and $S_{R}$ are the electricity supply functions for NRE and RE technologies, $D_{R}$ is the annual incremental U.S. electricity demand that could be fulfilled by RE technologies, and $D_{T}$ is the total annual incremental U.S. electricity demand. To simplify the analysis, we assume infinitely elastic supply and infinitely inelastic RE demand. In this case, the shaded area in Figure 6 shows the surplus in the current year from RE technologies that are able to provide energy quantity $q$ at cost $P_{R}$ instead of at cost $P_{F}$. The surplus is simply consumers' cost savings from replacing the higher cost NRE electricity with the lower cost RE electricity.

\section{Figure 6: A Simplified U.S. Electricity Market}

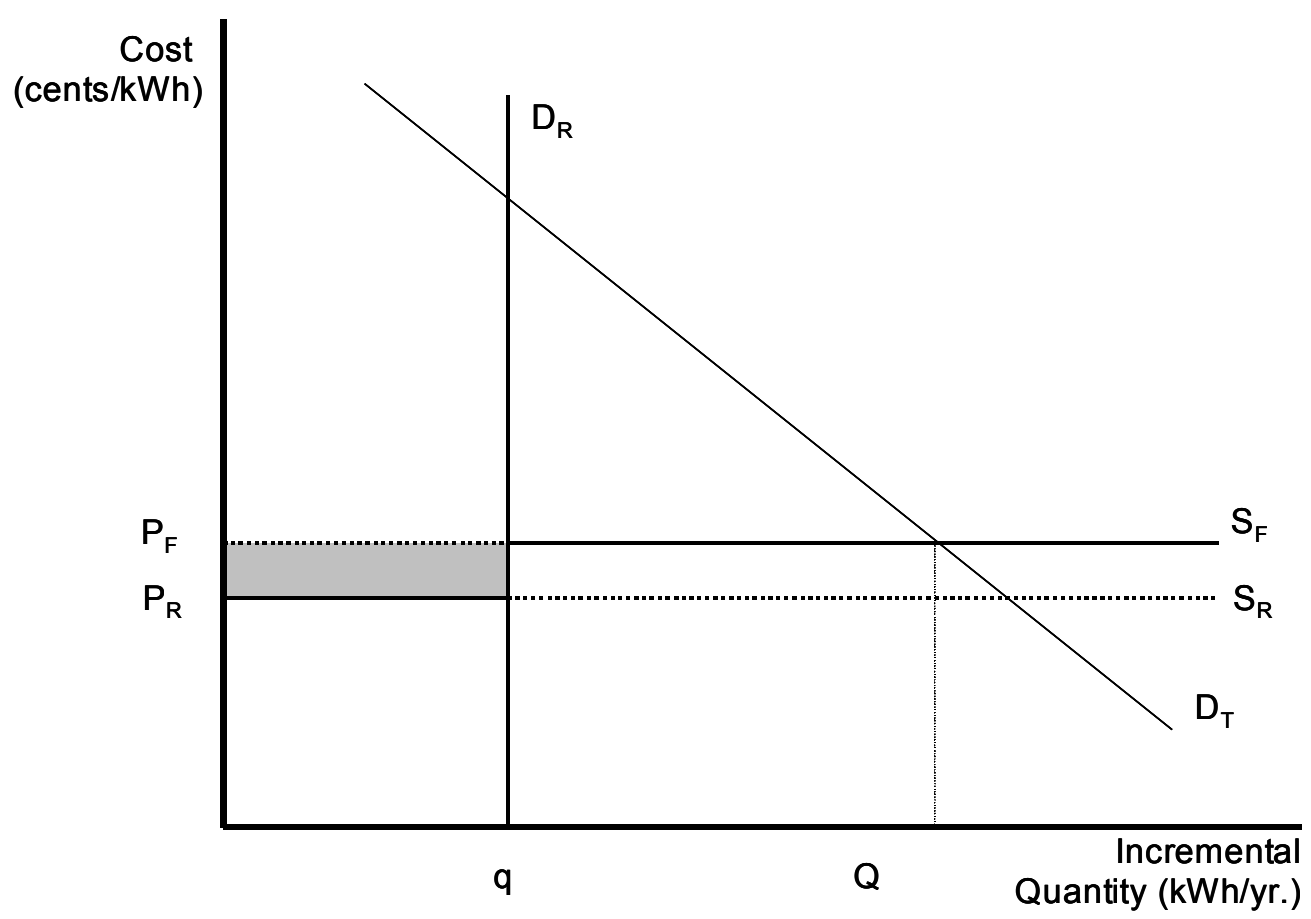

\footnotetext{
${ }^{5}$ Of course, this is a simplification that ignores marginal transmission and distribution expenditures. See fn 11 for a discussion of how to model these expenditures within this framework.

${ }^{6}$ This cost includes initial capital expenditures, operating expenses, taxes, debt payments, and returns to equity investors.
} 
Taking the current time period as zero, the NPV of the future cash flows created by RE technologies, if they were to be installed today and annually hereafter at rate $q$, is the difference between the expected cost of meeting current and future incremental electricity demand using the most cost-competitive RE technology and the expected cost of meeting current and future incremental demand using the most cost-competitive NRE technology:

$$
E\left[V\left(P_{F_{0}}, P_{R_{0}}\right)\right]=\int_{0}^{\infty} P_{F_{0}} e^{(\alpha-\hat{\alpha}) t} q_{t} \mathrm{~d} t-\int_{0}^{\infty} P_{R_{0}} e^{(\gamma-\hat{\gamma}) t} q_{t} \mathrm{~d} t
$$

In this equation, $\hat{\alpha}$ and $\hat{\gamma}$ are risk-adjusted discount rates, $\alpha$ is the expected rate of change of the cost of NRE electricity, $\gamma$ is the expected rate of change of the cost of RE electricity after switchover, and $q_{t}$ is the incremental electricity demand at time $t$ met by RE technologies. ${ }^{8,9}$ The future costs of NRE electricity, $P_{F}$, and RE electricity, $P_{R}$, are uncertain. ${ }^{10}$

For simplicity, we assume incremental electricity demand to be constant at rate $q$ in all future periods. Then, given deployment time zero, the initial demand for RE will be $q$, and $q_{t}=q+q t$ for all subsequent periods $t$. If we assume that $\alpha<\hat{\alpha}$ and $\gamma<\hat{\gamma}$ to avoid infinite present values or division by zero, then Equation 1 simplifies to

$$
E\left[V\left(P_{F_{0}}, P_{R_{0}}\right)\right]=\frac{P_{F_{0}}}{(\hat{\alpha}-\alpha)} q\left[1+\frac{1}{(\hat{\alpha}-\alpha)}\right]-\frac{P_{R_{0}}}{(\hat{\gamma}-\gamma)} q\left[1+\frac{1}{(\hat{\gamma}-\gamma)}\right]
$$

This value may be positive or negative, depending on the current costs of RE and NRE electricity, their expected rates of change over time, and their relative discount rates. A negative

\footnotetext{
${ }^{7}$ By examining the value of future cash flows, assuming that RE technologies are installed today, we are constructing the typical "now-or-never" NPV. This NPV does not take into account the optimal timing of RE deployment. To evaluate the NPV of the RE program assuming that deployment can be made at some time in the future, rather than only "now or never," we can adjust our DCF model to allow for an arbitrary deployment start time $\tau$, adding annual $\mathrm{R} \& \mathrm{D}$ costs at rate $M$ while waiting to invest. We can estimate the optimal time of investment by maximizing our DCF equations with respect to start time $\tau \geq 0$, using numerical iterations to find the optimal time $\tau^{*}$. We perform this calculation later in the paper.

${ }^{8}$ The costs include capital recovery, so that the technology can be seen as being perpetually installed, allowing the upper limit on the integrand to be infinity.

${ }^{9}$ In Equation 1, we ignore any tax deductibility of energy costs as an input to industrial production, since this is simply a transfer between economic parties.

${ }^{10}$ Since we abstract from the daily and seasonal trends in wholesale power prices, at issue is simply the uncertainty around the expected annual drift in electricity costs.
} 
value indicates that immediately deploying RE technologies to meet incremental electricity demand will lower consumers' expected aggregate present wealth.

There are certain real-world complications that we now introduce into this valuation model. It is often hypothesized that the transition from a NRE-only electricity market to a mixed NRE-RE electricity environment will involve market conditioning and other infrastructure expenditures that take time to complete. These "switching" expenditures are expected to be necessary in order to eliminate technical, institutional, and market barriers (OTA 1995), and to overcome technological lock-in (Arthur 1989) enjoyed by NRE technologies. In this model, we define total switching costs remaining at time $t$ as $K_{t \cdot}{ }^{11}$ Initial switching costs are $K_{0}$, which we will denote as $K$. Annual switching expenditures are made at up to maximum rate $I_{\max }(\$ / \mathrm{yr}$.). We take the rate of switching expenditures, $I$, to be a linear function of the cost of NRE electricity: $I=i P_{F .}{ }^{12}$ We assume these to be irreversible expenditures: if RE technologies do not take off, $\Sigma I$ cannot be recovered, and so $i \geq 0$. We take $i$ to be the control variable, and the expected time to deployment at time $t$ for $i>0$ is $T_{t}\left(k_{t}\right)=\frac{\ln \left(1+\frac{\alpha k_{t}}{i}\right)}{\alpha}$ years, where $k_{t}=K_{t} / P_{F t}$. We assume that there is a maximum rate of switching expenditure, such that $0 \leq i \leq i_{\max }<\infty$. This means that $\mathrm{RE}$ technologies cannot be instantaneously deployed, with the minimum expected time to initial deployment $T_{t_{\text {min }}}\left(k_{t}\right)=\frac{\ln \left(1+\frac{a k_{t}}{i_{\max }}\right)}{\alpha}$ years. ${ }^{13}$ No RE supply is possible until the entire switching cost $K$ is spent, after which $q$ units of RE become available for installation in each year.

We also assume that prior to the completion of switchover, the cost of RE electricity changes at the rate $v$ due to continued R\&D. DOE currently manages a portfolio of RE R\&D projects. Therefore, $v$ represents the rate of change associated with the entire RE R\&D portfolio. The portfolio rate of change is expected to be greater than the rate associated with an individual RE technology because there are considerable advantages to optimally managing interrelated $R \& D$

\footnotetext{
${ }^{11}$ Since there is no autonomous inflation in $K$, our model assumes that, as we wait to invest, we gain technological efficiency with respect to the real deployment costs, ceteris paribus. Since RE electricity costs are expected to improve relative to NRE electricity costs, this seems a reasonable assumption. Also, $K$ can include transmission and distribution and other electricity infrastructure expenditures that may be required for large-scale RE technology deployment.

12 The intuition behind this functional form is that the maximum rate of deployment of RE will be faster when fossil fuel prices are higher.

${ }^{13}$ Where there is the option to delay deployment, RE technology value is maximized by switching at the maximum possible rate. This is because the switching cost is assumed to be constant through time, so that the present value of switching costs are lower the longer they can be delayed. Once immediate deployment becomes optimal, instantaneous switching is preferred to a market-conditioning scheme that takes time.
} 
projects. ${ }^{14}$ For simplicity, we also assume that once the switching period is complete and the electricity market is prepared to adopt RE technologies, federal RE R\&D program funding will be curtailed. ${ }^{15}$ Thus, after switchover, the rate of change, $\gamma$, is a function of market, rather than $\mathrm{R} \& \mathrm{D}$ activities.

We also must charge against the program annual R\&D expenditures, $M(\$ / \mathrm{yr}$.) during the switching period. ${ }^{16} \mathrm{We}$ assume that $M$ is the linear function $M=m P_{F}$, where $m$ is a given positive constant. ${ }^{17}$ We will later allow for the optimization of $M$.

Taking these switching cost and switching time complexities into account, the NPV of the RE technologies, if switchover were to begin today at the maximum rate of expenditure, $I_{\max }$, is

$$
\begin{gathered}
E\left[F\left(P_{F_{0}}, P_{R_{0}}, K\right)\right]=\frac{P_{F_{0}}}{(\hat{\alpha}-\alpha)} e^{(\alpha-\hat{\alpha}) T_{0 \min }\left(k_{0}\right)} q\left[1+\frac{1}{(\hat{\alpha}-\alpha)}\right] \\
-\frac{P_{R_{0}}}{(\hat{\gamma}-\gamma)} e^{(\nu-\hat{\gamma}) T_{0 \min }\left(k_{0}\right)} q\left[1+\frac{1}{(\hat{\gamma}-\gamma)}\right]-\int_{0}^{T_{0 \min }\left(k_{0}\right)} P_{F_{0}}\left(i_{\max }+m\right) e^{-\hat{\alpha} t} \mathrm{~d} t \\
=\frac{P_{F_{0}}}{(\hat{\alpha}-\alpha)} e^{(\alpha-\hat{\alpha}) T_{0 \text { min }}\left(k_{0}\right)} q\left[1+\frac{1}{(\hat{\alpha}-\alpha)}\right] \\
-\frac{P_{R_{0}}}{(\hat{\gamma}-\gamma)} e^{(v-\hat{\gamma}) T_{0 \min }\left(k_{0}\right)} q\left[1+\frac{1}{(\hat{\gamma}-\gamma)}\right]-\frac{P_{F_{0}}\left(i_{\max }+m\right)}{(\hat{\alpha}-\alpha)}\left[1-e^{(\alpha-\hat{\alpha}) T_{0 \min }\left(k_{0}\right)}\right]
\end{gathered}
$$

Under the NPV framework, the only choices are to initiate switching period now or never. The optimal investment rule is to immediately proceed with deploying RE technologies if $F>0$. If $F$ $<0$, it is optimal to instead abandon the federal RE R\&D program because RE technologies, net of R\&D expenditures, are uneconomic.

\footnotetext{
${ }^{14}$ See Childs et al. (1998). There are, in essence, dynamic external informational economies that make the value of optimal management of the portfolio greater than the sum of optimal management of the individual projects.

${ }^{15}$ This need not be the case. RE researchers anticipate the need for continued public support after RE deployment has occurred in order to stabilize infant RE industries and promote continued technological development.

${ }^{16}$ We assume that R\&D funding continues during the market-conditioning phase.

${ }^{17}$ The parameter $m$ can be thought of as a response coefficient, with our functional form reflecting the political reality that RE R\&D funding has historically been a function of the price of fossil fuels. The higher $m$, the more sensitive $R \& D$ spending to changes in fossil fuel prices.
} 
Since the NPV function above is linear homogeneous in costs and $K$, it is convenient to express these valuation functions using the cost of NRE electricity as the numeraire. That is,

$$
\begin{aligned}
G\left(p_{0}, k_{0}\right)= & \frac{1}{(\hat{\alpha}-\alpha)} e^{(\alpha-\hat{\alpha}) T_{0_{\min }}\left(k_{0}\right)} q\left[1+\frac{1}{(\hat{\alpha}-\alpha)}\right] \\
& -\frac{p}{(\hat{\gamma}-\gamma)} e^{(\nu-\hat{\gamma}) T_{0_{\min }}\left(k_{0}\right)} q\left[1+\frac{1}{(\hat{\gamma}-\gamma)}\right]-\frac{i_{\max }+m}{(\hat{\alpha}-\alpha)}\left[1-e^{(\alpha-\hat{\alpha}) T_{0_{\min }}\left(k_{0}\right)}\right]
\end{aligned}
$$

where $p=P_{R} / P_{F}$, and $F(\bullet)=P_{F} G(\bullet)$. The value of $F$ can then, for a given level of $k$, be plotted as a linear function of the current ratio of electricity costs, $p$.

\section{Discounted Cash Flow Parameter Values}

As we indicated above, we believe it is important to estimate the DCF value of RE technologies because of the insights that can be gained through the economic modeling process. As such, the usefulness of this exercise lies in the insights provided by the models, more than in the specific numerical values. This is particularly important to remember in the context of estimating model parameters. Many of the parameters required for this analysis are complex enough to warrant their own independent research effort. As such, the goal here is to develop simplified parameter estimates that can be used to glean insights from the valuation model.

One of the most contentious issues in calculating any net present value of a risky cash flow stream is the estimation of appropriate discount rates $\hat{\alpha}$ and $\hat{\gamma}$. Here, the relative level of the two discount rates also affects the value of RE technologies. For example, if NRE generation is less risky (in a systematic sense) than RE generation, the discount rate for NRE technologies will be lower. This increases the present value of these costs - risk in this case is valuable to the consumer, since costs provides a hedge over deviations in wealth, with costs being high when income is high, and low when income is low-and provides an incentive to switch to the riskier RE technologies. Awerbuch and Deehan (1995) find that fossil fuel prices may indeed be negatively correlated with the market, making them more risky than renewables, whose cost uncertainty we assume to be technical, and therefore unsystematic. However, they find that the Beta of fossil fuel-generated electricity is approximately zero. Bessembinder and Lemmon 
(1999) speculate that wholesale electric power prices have no systematic risk, which is in agreement with Awerbuch and Deehan, and we have found that near-term natural gas futures prices during the past six years show no significant trend and no correlation with the market. ${ }^{18}$ From this we assume that the appropriate discount rate for fossil energy is the risk-free rate. Since the uncertainties in the cost of supplying renewable electric are technical, and therefore unlikely to be systematic, we also assume a risk-free discount rate when discounting these costs.

The values of the parameters in the DCF model, Equation 4, are presented in Table 1. All values are expressed in nominal terms. Because wind technologies are currently the most costcompetitive RE technologies in the bulk electric-power market, the parameter values in Table 1 were derived using wind energy as the representative RE technology. We recognize the existence of niche markets in which other RE technologies currently hold a competitive advantage. PV technologies, for example, often have an advantage in providing electricity in offgrid, or distributed energy, applications. We do not examine these niche markets here. We expect that the cost-competitiveness of all of the technologies within the federal RE R\&D portfolio will continue to improve over time, perhaps even to the extent that wind energy may not be the most cost-competitive RE technology during the analysis period. We therefore allow for the possibility that another RE technology may become the representative technology within the forecast horizon, and this possibility is reflected in the parameter values $v$ and $\gamma$.

\footnotetext{
${ }^{18}$ The annualized rate of increase in daily first nearby futures prices from June 28, 1994, through June 28, 2000, is $0.19 \%$, and a regression of futures returns on the returns to the S\&P 500 Index yields an insignificant slope parameter. Both results indicate a lack of systematic risk in natural gas prices, from which we deduce that changes in levelized costs of natural gas-fired electricity generation is unsystematic.
} 
Table 1: DCF Model Parameter Values

Parameter

Model

Symbol

Current renewable

$\mathrm{P}_{\mathrm{R} 0}$

Value

Notes

electricity cost

4.5 cents $/ \mathrm{kWh}$

The approximate current cost of Class 4 wind

\author{
ectricity cost
}

Renewable electricity
annual rate of cost

$v, \gamma \quad-1 \% / \mathrm{yr}$. (assuming an

reduction (2000-2020)

$\hat{\gamma}$

Renewable discount rate

Current fossil-fuel

$\mathrm{P}_{\mathrm{F} 0}$

electricity cost

Fossil-fuel electricity
annual rate of cost

$\alpha$

$0.3 \% / \mathrm{yr}$.

increase (2000-2020)

Fossil-fuel discount rate

$\hat{\alpha}$

Annual incremental

$7 \%$

3.5 cents $/ \mathrm{kWh}$

electricity demand met by

renewables annual \$300 million

R\&D budget) before

implementation ( $v$ ),

$0 \% / y r$. after

implementation $(\gamma)$

(assumes supply

constraints offset

technological

improvements).

energy in 2000, according to the Electric

Power Research Institute's renewable electric

Technology Characterizations (RETC) (EPRI

1997). The actual cost of generation from both renewable and nonrenewable systems will vary depending upon resources and financial and ownership structure.

$v$ is an estimate of the marginal productivity of RE R\&D efforts. This estimate is consistent with the technical goals outlined in the RETC, and the report of the President's Committee on Science and Technology (PCAST 1997), both of which indicate that current $R \& D$ funding levels must be roughly doubled to achieve program objectives. The estimate of $\gamma$ assumes that market learning effects and international $R \& D$ efforts cause the cost of RE to remain flat, with technological gains just offsetting inflation in costs.

The approximate risk-free discount rate at the time that we developed this model. It has since declined considerably.

The estimated marginal cost of electricity generation from a natural gas advanced combined-cycle generator in 2005 (EIA 1999, p. 67)

This is the rate of marginal generation cost increase for natural gas-fired, combined-cycle generation. This rate assumes mid-range natural gas prices (EIA 1999, p. 67).

The approximate risk-free discount rate at the time that we developed this model. It has since declined considerably.

37.3 billion $\mathrm{kWh} / \mathrm{yr}$.

This value assumes that $50 \%$ of annual incremental U.S. demand will be met by RE technologies. 37.3 billion $\mathrm{kWh} / \mathrm{yr}$. is 
Table 1: DCF Model Parameter Values

\begin{tabular}{|c|c|c|c|}
\hline Parameter & $\begin{array}{l}\text { Model } \\
\text { Symbol }\end{array}$ & Value & Notes \\
\hline Total switching cost & K & $\$ 10$ million & $\begin{array}{l}\text { approximately equal to } 50 \% \text { of expected } \\
\text { annual incremental demand between } 2000 \text { and } \\
2020 \text {. This value is reasonable given that total } \\
\text { U.S. wind resource potential (for Class } 4 \text { and } \\
\text { greater) is estimated to be more than } \\
1.5 \text { trillion kWh/yr. (Elliot and Schwartz } \\
\text { 1993). } \\
\text { A rough estimate of the cost of legislation and } \\
\text { standards that may be required to facilitate the } \\
\text { switchover to renewable electric technologies. } \\
\text { This value is small relative to the level of RE } \\
\text { implementation since it is assumed that } \\
\text { markets will operate efficiently, thus } \\
\text { minimizing switching expenditures. }\end{array}$ \\
\hline $\begin{array}{l}\text { Annual maximum } \\
\text { switching expenditure }\end{array}$ & $I_{\max }$ & $1 / 3$ total switching costs & $\begin{array}{l}\text { A switchover time }\left(\mathrm{T}_{0 \mathrm{~min}}\right) \text { of approximately } 3 \\
\text { years is used. }\end{array}$ \\
\hline Annual R\&D funding & $\mathrm{M}_{0}$ & $\$ 0.3$ billion & $\begin{array}{l}\text { The approximate federal FY } 2000 \text { RE R\&D } \\
\text { funding level. }\end{array}$ \\
\hline
\end{tabular}




\section{Discounted Cash Flow Model Results}

Using Equation 4 and the parameter values presented in Table 1, the value of RE technologies is estimated to be negative $\$ 35.3$ billion given the current RE/NRE cost ratio of approximately 1.29 $(4.5 \notin / \mathrm{kWh} \div 3.5 \notin / \mathrm{kWh})$. For these parameter values, the DCF model indicates that the RE technologies are uneconomic and therefore the RE R\&D program should be abandoned if the current cost of electricity for the most competitive RE technology is more than $13 \%$ higher than the current NRE cost of electricity of $3.5 \phi / \mathrm{kWh}$. This result seems to buttress the arguments of RE opponents who claim that the national RE R\&D program should be abandoned.

\section{Figure 7: The NPV of RE Technologies as a Function of the Current Electricity Cost Ratio}

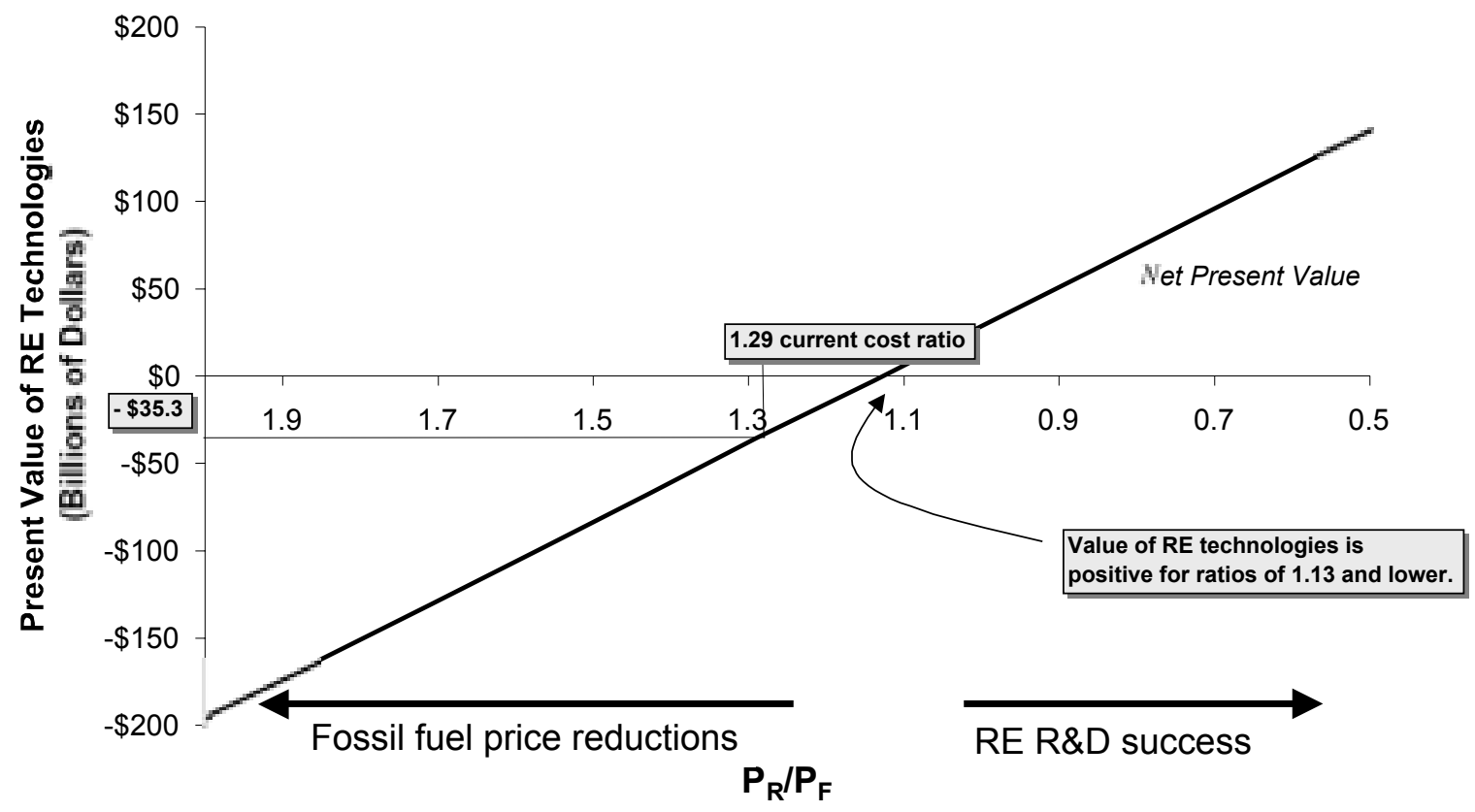

The NPV of RE technologies, as a function of the current ratio of the costs of RE and NRE electricity, is presented in Figure 7. This figure provides insights into the perceived value of RE technologies given changes in the cost of RE and the cost of NRE. Decreases in the cost of RE electricity due to the technical success of the RE R\&D program, or increases in the cost of NRE electricity due to fossil fuel-price increases, appear as rightward movements along the horizontal axis. Decreases in the cost of NRE electricity due to fossil price decreases appear as a leftward movement along the horizontal axis. This shows how reductions in the price of fossil fuels 
decrease the value of RE technologies and may create the perception, on an NPV basis, that continued R\&D funding is unwarranted. As we noted above, the NPV becomes positive for cost ratios of 1.13 or lower.

\section{Discounted Cash Flow Shortcomings}

Using the parameters from Table 1, the DCF model indicates that the RE R\&D program should be abandoned. This may be disconcerting to RE technology advocates who take exception with the valuation of RE technologies from a narrowly defined market-based perspective. This is a legitimate concern, particularly since there is strong evidence that the potential social, environmental, and auxiliary economic benefits of RE technologies are greater than the marketbased benefits. The central purpose here, however, is to determine the value of RE technologies from a narrowly defined economic perspective without introducing benefits that are external to the electricity market. Note that, if indeed RE technologies provide a favorable return on a market basis, then the need to introduce environmental and auxiliary economics benefits is diminished to the extent that these benefits will only serve to make an already favorable investment even more attractive.

Recall, however, that one of the primary missions of the federal RE R\&D program is to "reduce U.S. vulnerability to energy supply disruptions" (EERE 2000). The DCF model assumes that RE market conditioning begins immediately, even though RE electricity costs are greater than NRE electricity costs. During the three-year switching period, RE electricity costs are assumed to decline by $1 \%$ per year due to ongoing federal R\&D efforts, while NRE electricity costs are assumed to climb by $0.3 \%$ per year. After installation is complete and federal R\&D efforts are curtailed, RE electricity costs are assumed to remain constant. Given these parameter assumptions, RE technologies will eventually pay off in terms of lower electricity supply costs, but those benefits do not begin for 74 years. With the benefits of RE so far off, the present value of installing RE technologies now is negative. In fact, given these assumptions, the optimal policy is to delay deploying $R E$ and continue $R \& D$ funding until $R E$ technologies become more competitive, which will take about 25 years according to the DCF model. In fact, given these parameter assumptions, the NPV of RE technologies is maximized if deployment is delayed for 22.7 years while ongoing R\&D efforts reduce technology costs. The expected NPV of the RE 
technologies under this "commit in 22.7 years" deployment plan then rises to $\$ 4.8$ billion, net of the present value of ongoing $R \& D$ expenditures.

But even by assuming optimal deployment timing, we still do not address the full value of RE in mitigating the impact of fossil fuel-price increases. What are the chances that a fossil fuel supply disruption will occur during this timeframe and significantly increase the cost of NRE electricity? What is the value of having RE systems available as "backstop" technologies in the event of severe fossil fuel-price increases? Unfortunately, these issues are not addressed within the DCF model. The DCF framework uses only mean values and disregards the potential for decision makers to create value by reacting to uncertainty. This is one of the most significant shortcomings of DCF analysis. This shortcoming means that the DCF framework is unable to directly quantify the insurance value of RE technologies. Clearly, a more insightful analytic framework is required to properly value these technologies.

The DCF framework has several other significant limitations when assessing technologies in which there is considerable technical and financial uncertainty and where R\&D is ongoing. First, since there is still scope for improving the economics of technologies under development, $R \& D$ continues - and these ongoing R\&D efforts must be evaluated. The sequential nature of $R \& D$ has led economists to reject the usual evaluation criteria, such as the NPV technique we used above, as a method of valuing ongoing R\&D programs (e.g., Roberts and Weitzman 1981). It is, rather, a dynamic programming problem. Second, given the uncertainty of the outcomes of the R\&D process, and the fact that the option to install the technologies limits the downsides from the RE technologies, there is considerable difficulty in assessing the risk - and therefore the discount rate - for the future benefit flows were the technologies under development to become economic. That is, we have difficulty evaluating the eventual payoffs to the R\&D effort using DCF. Third, the switchover to new RE technologies takes time, and the amount of time needed for the switchover is uncertain. This creates uncertainty about the deployment time, or "time-tobuild" as it is known in the real options literature. DCF analysis can allow for non-instantaneous investments, but has difficulty evaluating the value of an uncertain time-to-build (Ott and Thompson 1996). In addition, since there is a time to build, the riskiness of the project will change as the remaining amount of investment, and hence the project leverage, decreases (Berk et al. 1998). DCF analysis, which uses a constant discount rate for all period cash flows, does not take this changing risk into account. Finally, during technology switchover, the ratio of 
energy costs can vary, suddenly making the project uneconomic. The option to temporarily halt or even permanently abandon switchover midstream adds value. DCF techniques cannot value this flexibility.

It is important to note here that the shortcomings described above can be addressed by constructing a modified DCF model. For example, DCF techniques combined with analysis tools such as decision trees, in which probability distributions are assigned to uncertain variables and utility functions are used to specify risk preferences over uncertain outcomes, can be used to model the optionality of investments. We recognize this, and we acknowledge the strong body of high-quality analytic work in this arena. We believe, however, that the need to continually modify to the DCF framework in order to correct its deficiencies is an indicator of the need to adopt a new theory. In its basic form, the DCF framework simply does not capture many of the key aspects of many investment problems under uncertainty. We use the historical analogy of the astronomical practice of adding epicycles to the geocentric model of planetary motions. Eventually so many revisions are added that the model becomes too convoluted to be tractable. From our perspective, transition from the DCF to the real options framework is akin to the progression from the geocentric to the heliocentric theory.

\section{The Real Options Approach}

The real options approach, which uses the concepts embedded in financial options to value nonfinancial investment opportunities under uncertainty, is ideally suited to value RE technologies and determine the benefits of continued federal R\&D. In fact, economists already have successfully applied real options valuation techniques to R\&D investments and have found that the real options framework substantially clarifies the theory and practice of R\&D decision making. ${ }^{19}$ The seeds of real options theory were sown in 1973 when Myron Scholes, Robert Merton, and the late Fischer Black made a Nobel prize-winning breakthrough in how to price financial options. The Black-Scholes formula transformed financial options trading and helped create a global derivatives business. Stewart C. Meyers of the Massachusetts Institute of Technology coined the term "real options" in 1984 to describe the valuation of non-financial assets using options theory. Academics have long recognized that real options can bring the

\footnotetext{
${ }^{19}$ See Berk et al. (1998), Childs et al. (1998), Childs and Triantis (1999), Huchzermeier and Loch (1998), Kumaraswamy (1997), Laughton et al. (1993), Ott and Thompson (1996), Schwartz and Moon (2000), Smit and Trigeorgis (1997), and Willner (1995).
} 
discipline of financial markets to bear on strategic investment decisions. However, due to its complex nature, the real options approach has only recently made its way out of academia and into the hands of decision makers.

In order to understand how one might use the real options approach to evaluate the portfolio of available RE technologies as an option whose value is affected by the rate of R\&D expenditures, consider an option (or a right) to irreversibly invest in a particular asset (the underlying asset) at a specific price (the exercise price or investment cost) at or prior to a predetermined date in the future (the expiration date). This is the framework under which financial call options are created and valued, and under which we can evaluate RE technologies. Given that, among the technologies within the federal RE R\&D portfolio, a most cost-competitive RE technology exists at any moment, we have the option at each instant to meet incremental energy demand with REgenerated electricity. The expected payoff to meeting electricity demand is the present value of any perpetual cost savings from installing the most cost-competitive RE technology. These savings are equivalent to the value of the underlying asset in a financial option. Receiving these cost savings requires that the RE technology be deployed, which involves an irreversible investment in infrastructure and other switching costs. This is the exercise price. Irreversibility of the switching costs means that once the deployment is made, the costs cannot be recovered. ${ }^{20}$ With RE, the option is to invest in and install RE technology and infrastructure, receiving the benefits of the difference in cost between RE generation and NRE generation. The option is virtually perpetual, since the RE technologies that have been developed have a long shelf life. ${ }^{21}$ The final component of the option analogy is the uncertainty in future value of the underlying asset. For RE technologies, the benefits depend on the difference between RE and NRE in cost of supply. This difference can be affected by ongoing federal RE R\&D expenditures, which can be seen as a holding cost while waiting to exercise the option, and by movements in the relative generation costs of RE and NRE. This uncertainty is known as asset value volatility, and is equivalent to the volatility of the underlying asset in financial options.

An option's payoff, if exercised at any moment, is the difference between the underlying asset's value at that moment and the present value of the exercise price. This difference might be considered the "now-or-never" NPV of the investment. If the exercise price is lower than the

\footnotetext{
${ }^{20}$ If renewable energy turns out to be uneconomic, the infrastructure, while perfectly functional, will have no salvage value.

${ }^{21}$ In fact, in our calculations below, we allow the option to switch to RE to stay alive even if the RE R\&D is curtailed.
} 
asset value, then the payoff from investing, or exercising the option, will be positive; and if the exercise price is higher than the asset value, the payoff will be negative. In terms of option pricing, the former option is "in the money," while the latter is "out of the money." Out-of-themoney options are equivalent to negative value NPV projects, only they have holding value due to future uncertainty and rare events. This is because the downside from holding the option is limited to the option holding costs, if any (the investment, if it would be a loss-making venture, need not be undertaken), while the upside is always available. In other words, even if the future value of an asset is expected to be very low, a financial option on the asset can still have value because of the possibility of a future increase in the value of the underlying asset.

These same observations carry through to real options. In particular, the downside of RE technologies is the continued expenditures on $R \& D$ while the option is being held, while the upside is the potential value that RE technologies could generate in a high fossil fuel-price environment. As with financial options, it is the option to wait and the volatility of the value of the cost savings that creates hold value above and beyond the NPV of the option, revealing that the option to postpone the deployment of RE technologies of uncertain future value has current value that cannot be measured using DCF techniques. Generally, the more negative the NPV and the more volatile the environment, the more valuable the option to wait. Given the current uncertainty regarding the future costs and availability of fossil fuels, we would expect the RE deployment option to have considerable value. ${ }^{22}$

In summary, as an alternative to the DCF approach, we can view RE deployment as a real option that is currently out of the money-immediate exercise yields a negative net payoff as indicated by our "now or never" NPV value of negative $\$ 35.3$ billion. However, given the option to postpone RE deployment, given the option to undertake cost-reducing RE R\&D while waiting, and given the possibility that RE technologies may produce energy cost savings should NRE electricity costs unexpectedly rise relative to the cost of RE, having the option to install the RE technologies in the future can be a valuable insurance policy. In order to calculate this insurance value, we can, through real options analysis, weigh up the value of the deployment option versus any ongoing R\&D expenditures.

\footnotetext{
${ }^{22}$ We cannot be assured of this, though. Many real options have holding and abandonment costs, which can make their value negative. This is in stark contrast to financial options, which are always valuable.
} 


\section{The Real Options Model}

Starting with the DCF model outlined above, we can model the value of RE technologies as a real option on energy cost savings. In doing so, we build upon real options models by Ott and Thompson (1996) and Schwartz and Moon (2000). The derivation of our real options model from DCF Equation 4 is presented in Appendix A.

\section{Real Options Parameter Values}

In the process of identifying the precise nature of the future economic uncertainty in our real options model, we introduce several new important parameters that are not included in the DCF model, Table 1. The values of the additional parameters included in the real options model are presented in Table 2.

Table 2: Real Options Model Uncertainty Characterization Parameters

\begin{tabular}{|c|c|c|c|}
\hline Parameter & $\begin{array}{l}\text { Model } \\
\text { Symbol }\end{array}$ & Value & Notes \\
\hline $\begin{array}{l}\text { Renewable electricity } \\
\text { annual rate of cost } \\
\text { reduction as a function of } \\
\text { R\&D funding }\end{array}$ & $v\left(\mathrm{M}_{0}\right)$ & $\operatorname{Max}\left(-0.033 * \mathrm{M}_{0},-.04\right)$ & $\begin{array}{l}\text { An estimate of the marginal productivity of RE R\&D } \\
\text { efforts. This estimate is consistent with the technical } \\
\text { goals outlined in the RETC, and the report of the } \\
\text { President's Committee on Science and Technology } \\
\text { (PCAST 1997), both of which indicate that current } \\
\text { R\&D funding levels must be roughly doubled to } \\
\text { achieve program objectives. We assume that the } \\
\text { maximum rate of RE cost decline is } 4 \% \text { yr. This } \\
\text { reflects the our belief that: (1) there is a maximum } \\
\text { funding level that can be absorbed given the current } \\
\text { RE R\&D infrastructure; and (2) even given higher } \\
\text { funding levels it still takes time to achieve R\&D } \\
\text { success. }\end{array}$ \\
\hline $\begin{array}{l}\text { Volatility surrounding the } \\
\text { renewable electricity } \\
\text { annual rate of cost } \\
\text { reduction as a function of } \\
\text { R\&D }\end{array}$ & $\sigma_{\mathrm{R}}\left(\mathrm{M}_{0}\right)$ & $\begin{array}{l}.009 / \mathrm{M}_{0} \\
\text { for } \mathrm{M}_{0} \text { greater than .6, } \\
\text { and } \\
.045-.05 * \mathrm{M}_{0} \\
\text { for } \mathrm{M}_{0} \text { less than or equal } \\
\text { to } .6\end{array}$ & $\begin{array}{l}\text { We assume that additional } R \& D \text { spending decreases } \\
\text { the rate of uncertainty as to that rate of decline. The } \\
\text { reasoning here is that all uncertainty about RE } \\
\text { technology can be resolved given enough } R \& D \\
\text { spending. We also assume that RE } R \& D \text { has a } \\
\text { downside in that it locks investors into a }\end{array}$ \\
\hline
\end{tabular}


Table 2: Real Options Model Uncertainty Characterization Parameters

Parameter

Model

Symbol

Value

Notes

technological pathway and diminishing the ability to

adopt alternative RE technologies. There is an

intercept term (.045) in the volatility equation for

funding levels less than (or equal to) $\$ 0.6$ million. We assume that, at current budget levels, RE R\&D cost goals have a $95 \%$ chance of being achieved within a $25-30 \%$ band of accuracy. If $R \& D$ funding levels are doubled, RE R\&D cost goals have a $95 \%$ chance of being achieved within a $10-15 \%$ band of accuracy.

This is consistent with accuracy bands provided in the RETC (EPRI 1997).

Volatility surrounding the $\sigma_{\mathrm{F}}$

fossil fuel electricity

annual rate of cost

increase
In the past 20 years, average annual natural gas prices have exhibited a volatility of 0.17 . Since fuel costs represent approximately $65 \%$ of total electricity generation costs, we estimate the volatility of fossil fuel generation to be $0.11\left(.17^{*} .65\right)$. We use long-run volatility here (the volatility of average annual prices) rather than short-run volatility (the annualized volatility of daily prices) because the emphasis in this analysis is on long-run price trends. We assume arbitrage opportunities (such as forward contracts) exist that allow firms to purchase fossil fuels at average annual prices. Also, due to data availability constraints, we do not include the natural gas price increases that started in the second half of 2000 in our volatility calculations 


\section{Real Options Model Results}

Figure 8 shows again the current expected NPV of RE technologies given FY 2000 federal R\&D funding levels and an estimated annual incremental supply of 37.3 Billion $\mathrm{kWh} / \mathrm{yr}$. once RE technologies are deployed. The option value of RE technologies, given the current RE/NRE electricity cost ratio of 1.29 , is $\$ 30.6$ billion (2000 dollars). That is, in the presence of technical and market uncertainty, the future expected cost savings from eventual installation of RE electricity generation capacity have a present value of $\$ 30.6$ billion dollars, net of ongoing RE R\&D expenses.

For model comparison purposes, Figure 9 shows the value of RE technologies for the different models presented in this paper: DCF, DCF with optimal installation timing, and real options. The value of RE technologies increases by approximately $\$ 66$ billion (2000 dollars) when we move from the DCF model to the real options framework. The increase in value comes from two sources: optimal timing and insurance value. Since the expected NPV of RE technologies under an optimal deployment is $\$ 4.8$ billion, we can attribute approximately $40 \%((35.3+4.8) /(35.3+$ 30.6)) of the option value to optimal timing and $60 \%$ to insurance value.

In Figure 10, we distinguish between the RE technology value created by historical federal R\&D expenditures (FY 1974 - FY 2000), and future R\&D expenditures. This is important because the decision faced by policy makers today is whether to continue program funding (i.e. commit future dollars). We can disentangle the value created by historical and future R\&D expenditures by setting $M_{0}$, annual RE R\&D funding, to zero. Because $v\left(M_{0}\right)=-0.033^{*} M_{0}$, when $M_{0}=0, v=0$. Essentially, by doing this, we assume that past $R \& D$ expenditures were responsible for lowering the cost of RE electricity to its current level, and that future R\&D expenditures will be required to further lower the cost. ${ }^{23}$ When we set the level of annual RE R\&D funding to zero in our real options model, we discover that the net value of RE technologies decreases from \$30.6 to \$26.3 billion (2000 dollars) given the current RE/NRE cost ratio of approximately 1.29 . Thus, the expected net value of future RE R\&D expenditures is $\$ 4.3$ billion (2000 dollars).

\footnotetext{
${ }^{23}$ This simplification neglects RE cost improvements that may occur due to either economy-wide technological improvement or learning effects from RE production in the absence of future RE R\&D expenditures.
} 
Figure 8: The Option Value of the RE Technologies as a Function of the Current Electricity Cost Ratio

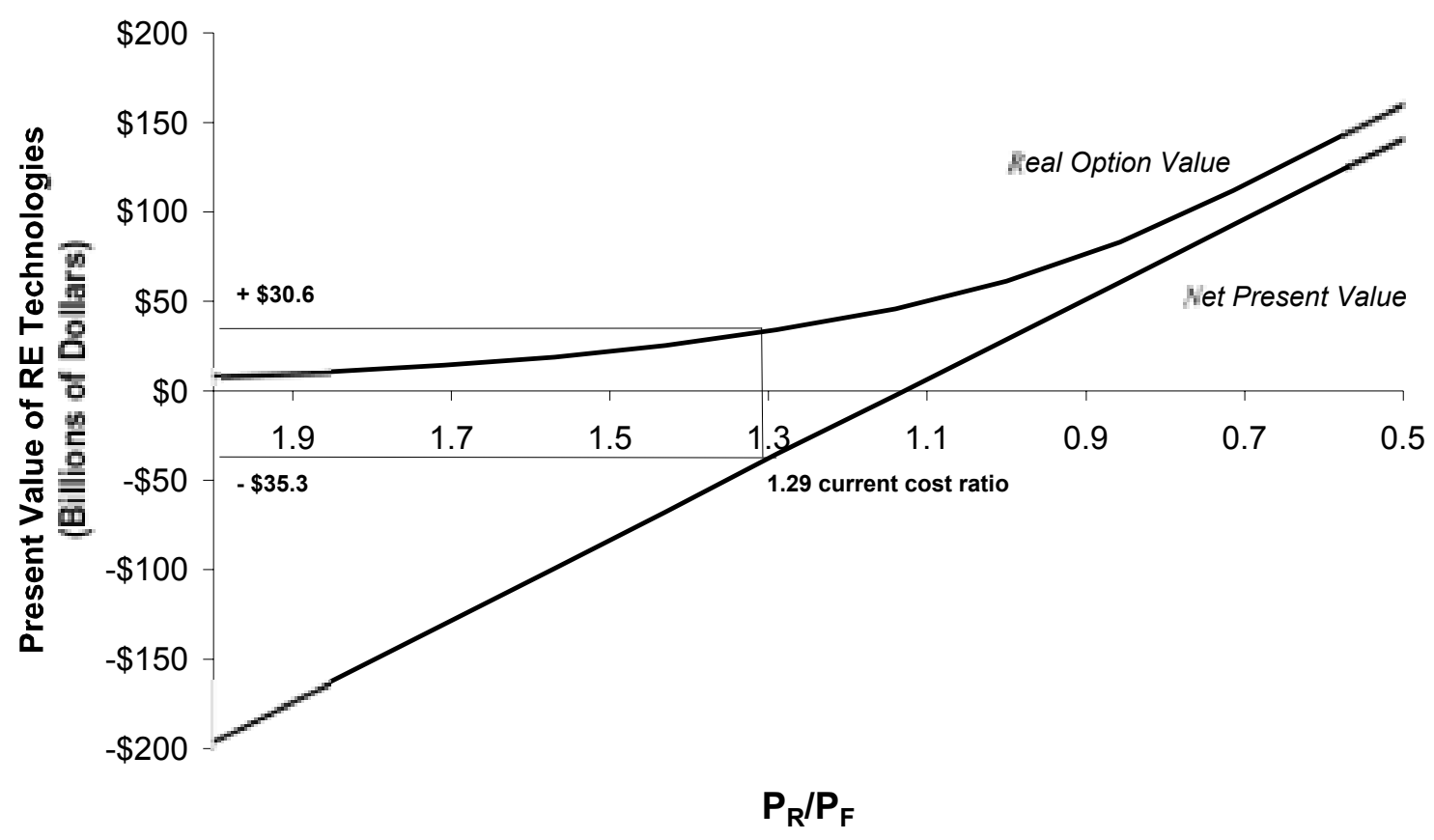

Figure 9: Current Value of the RE Technologies

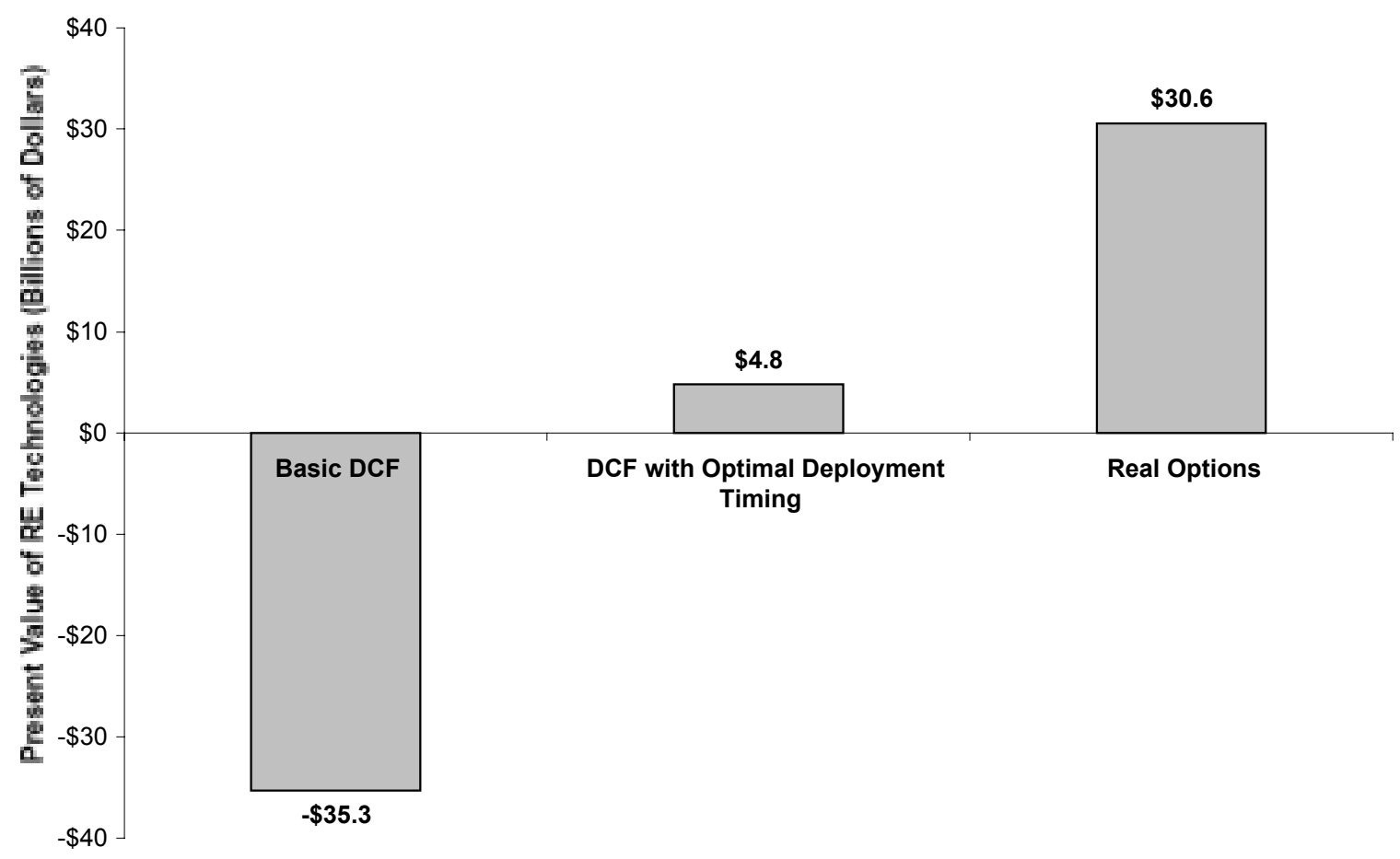




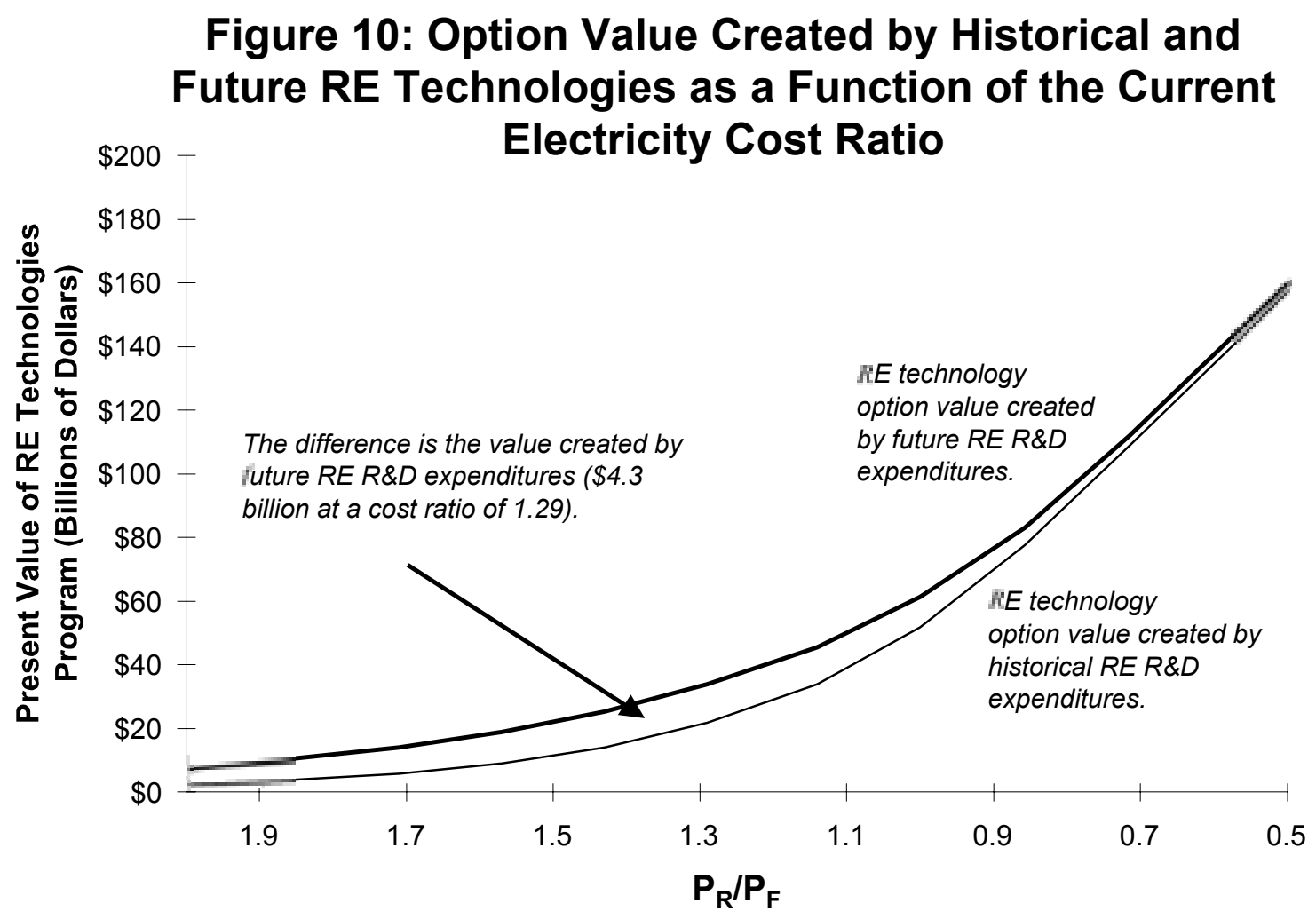

\section{Optimizing R\&D Expenditures}

We have shown that, given our parameter assumptions, RE technologies provide positive value to the nation from a narrowly defined market-based perspective. We now move on to the determination of the optimal annual RE R\&D budget. The objective of this section is to use the real options model developed above to determine the current funding rate, $M_{0}$, that maximizes the program value. This analysis depends heavily upon our assumptions about the marginal rate of R\&D productivity, $v\left(M_{0}\right)$. In particular, we assume that the more R\&D spending on RE technology, the faster the rate of decline in RE electricity costs over time. As indicated in Table 2, we assume that $v\left(M_{0}\right)=\operatorname{Max}\left(-0.033 * M_{0},-.04\right)$ where $M_{0}=$ the annual RE R\&D budget expressed in billions of dollars. This means that, at the current funding level of approximately $\$ 300$ million, the annual rate of decline in the cost of RE electricity is $1 \% / y r$. (the value we used in our DCF analysis). We also assume that the maximum rate of RE cost decline is $4 \% / y$. This reflects our belief that: (1) there is a maximum funding level that can be efficiently absorbed in the near to mid-term given the current RE R\&D infrastructure; and (2) given even higher funding levels, it still takes time to achieve R\&D success. Finally, we assume that additional R\&D spending decreases the rate of uncertainty as to that rate of decline. Additional R\&D spending 
thus increases the expected payoff from project deployment, but also decreases the uncertainty surrounding that payoff, each having an opposite effect on option value.

Throughout its existence, the federal RE R\&D program has experienced an inconsistent level of support from federal decision makers (Figure 2). The initial program budget in FY 1974 was \$72.6 million (2000 dollars). Spurred in part by the 1978-1979 petroleum price increases related to the Iranian Revolution, the federal RE R\&D program budget was gradually increased to a maximum of $\$ 1.56$ billion (2000 dollars) by FY 1980. During the Reagan-Bush administration (1980-1988), RE R\&D program funding was reduced by nearly $90 \%$. Under the direction of the Clinton-Gore administration, program funding leveled out in the $\$ 300$ million (2000 dollars) range. More recently, however, the Bush Administration has put downward pressure on the RE $R \& D$ budget by submitting lower budget requests. The question under examination here is whether a budget of approximately $\$ 300$ million/yr. (2000 dollars) represents the optimal RE $\mathrm{R} \& \mathrm{D}$ portfolio funding level.

The results of the options analysis on the optimal level of ongoing R\&D yields are presented in Figure 11. Figure 11 shows that increased R\&D spending does indeed pay off. At a deployment rate of 37.3 Billion $\mathrm{kWh} / \mathrm{yr}$. - once switchover is completed - the optimal annual rate of R\&D expenditures is approximately $\$ 1.2$ billion/yr. At this funding level, the present value of the RE technologies, net of R\&D expenses, climbs from $\$ 30.6$ billion to $\$ 50$ billion (2000 dollars). This analysis provides evidence to the effect that FY 1980's \$1.56 billion funding level was more close to the appropriate level than today's budget of approximately $\$ 300$ million. This analysis also lends support to the recommendations of the President's Committee of Advisors on Science and Technology, which asserted that significant RE R\&D budget increases would be required to "provide good prospects that RE technologies will be able to make large contributions to global energy during the first quarter of the next century." (PCAST 1997). 


\section{Figure 11: Current Value of RE Technologies as a Function of Ongoing Annual R\&D Spending}

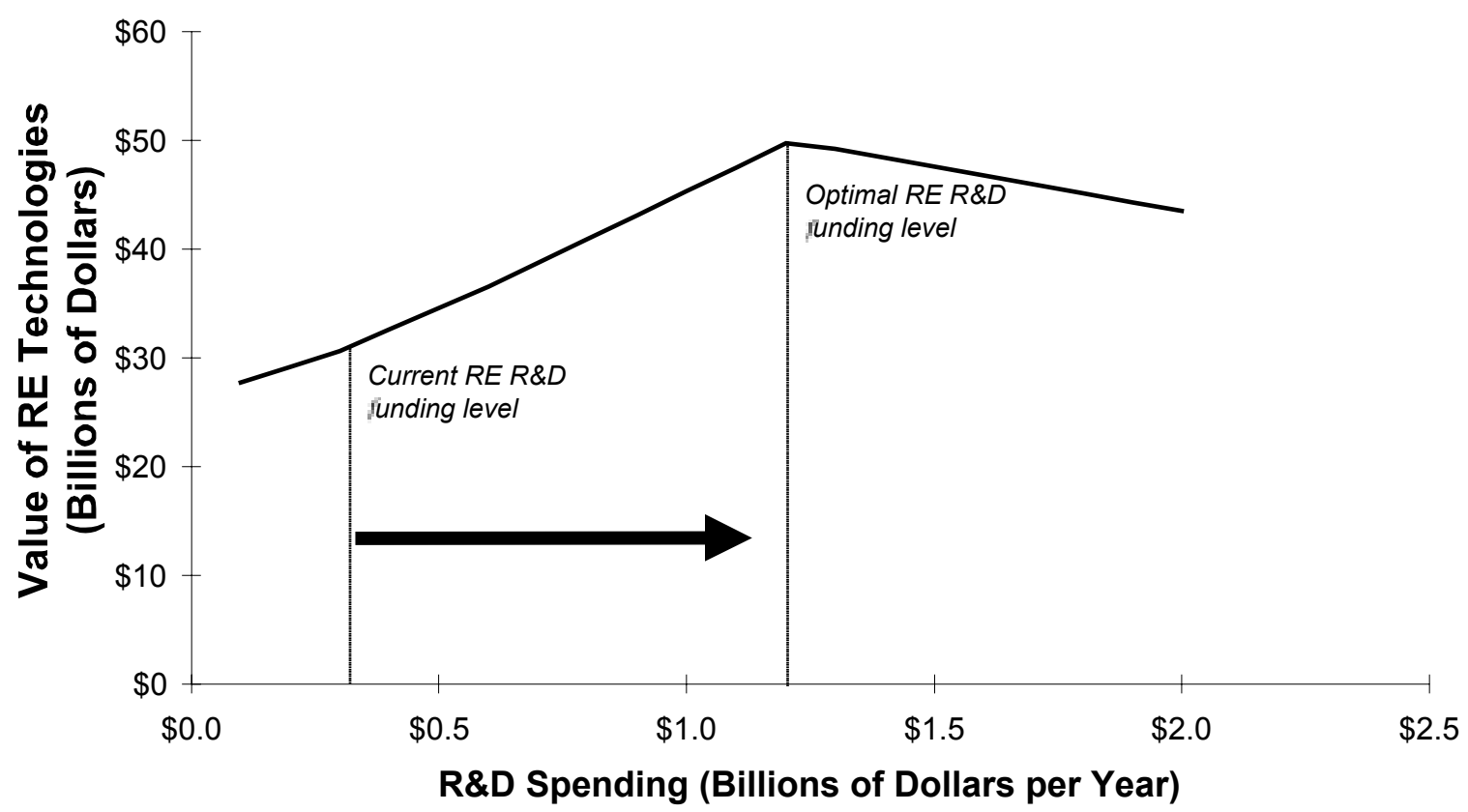

We must remark here that the optimal annual funding level of $\$ 1.2$ billion (2000 dollars) is a direct result of our decision to cap the maximum rate of RE electricity cost declines at $4 \% / \mathrm{yr}$. $\$ 1.2$ billion is simply the funding level where $0.033^{*} \mathrm{M}_{0}$ is approximately equal to 0.04 . Thus, the real insight provided by our model is that RE R\&D expenditures should be increased to the maximum level that can be absorbed by the federal RE R\&D complex without reducing marginal $R \& D$ productivity. The key question then is, can the federal RE R\&D complex sustain such a large budget increase? The answer, as reflected in the scientific literature and according to technology researchers, is yes. ${ }^{24}$ In fact, by examining data on R\&D investments and patent records, Margolis and Kammen (1999) found that energy R\&D investments and patents were highly correlated between 1976 and 1996. They found no evidence of declining marginal productivity of energy $R \& D$ investment during this period, regardless of the magnitude of $R \& D$ funding. According to Margolis and Kammen, this evidence "supports the hypothesis that the US under invests in energy-related $\mathrm{R} \& \mathrm{D}$, and illustrates that cut-backs in energy-related $\mathrm{R} \& \mathrm{D}$ have dramatic impacts on innovation in the energy sector." (p. 579). ${ }^{25}$

\footnotetext{
${ }^{24}$ Per personal correspondence, RE technology researchers at the National Renewable Energy Laboratory believe that the federal RE R\&D complex can sustain significant budget increases provided that the revised budgets include resources for R\&D capital expansion.

${ }^{25}$ Although Ambuj D. Sagar (2000) argues that Marolis and Kammen do not present a conclusive case in their analysis.
} 
It is important to underscore the importance of continued federal RE R\&D expenditures within the context of the ongoing restructuring of the U.S. electric utility industry. The uncertainty surrounding restructuring has initiated an exodus from energy $R \& D$ and long-range strategic planning in the electricity sector as a whole. This abandonment of R\&D is reflected in recent trends at investment-owned utilities (IOUs). For example, between 1994 and 1996, IOU investments in R\&D decreased by 35\%, from $\$ 650$ to $\$ 403$ million/yr. (FERC 1997). During the same period, the 10 largest IOU contributors to the Electric Power Research Institute (EPRI), the electric utility industry R\&D consortium, cut back their funding to EPRI by $47 \%$, from $\$ 130$ to \$69 million (FERC 1997). The transition to a more competitive market is expected to lead to continuing declines in private-sector investment in energy technology R\&D (Dooley 1998; GAO 1996). In this environment, federal RE R\&D has never been more important.

\section{Conclusions}

We have examined RE technologies from both the traditional DCF valuation perspective, a perspective that does not consider insurance value or optimal deployment timing, and the real options perspective, which draws upon insights from financial markets in order to value these RE benefits. We found that RE technologies are economically attractive from the real options perspective when optimal timing and the insurance value are considered. Further, using real option analysis, we determined that the optimal level of RE R\&D investment is $\$ 1.2$ billion/yr., approximately four times the program's FY2000 funding level.

We must, however, temper this result with a statement we made earlier. The usefulness of this exercise lies in the insights provided by the real options model, not in our final annual investment recommendation. The key insight here is that $\mathrm{RE}$ technologies hold a significant amount of value that cannot be detected by using traditional valuation techniques. Thus, in order to appropriately value these technologies and the benefits of continued $R \& D$ spending, we must adopt a more advanced valuation perspective such as real options analysis.

Even though our estimates of technology value are a function of our selected parameter values, which are subject to debate, we still feel that our estimates of RE technology value have been conservative. For example, we assume that the decision on future optimal RE R\&D levels is 
made now, and maintained until the option is completely exercised or until the option is abandoned. We could allow for dynamically varying R\&D funding levels, which would then create additional value by optimizing the level of R\&D. We also could allow for the switching to $\mathrm{RE}$ to be an increasing function of annual switching expenditures, permitting a form of adjustment costs, and set no exogenous upper limit to annual switching expenditures (Childs and Triantis 1999). This could add further value to RE technologies. Finally, we have not allowed for any reversibility of the RE technology deployment once it ultimately replaces fossil-fueled generation. Yet RE generation is partially reversible and this also would add value to RE technologies. In sum, our model could be extended to include optionality that would further increase the present value of cost savings from future RE technology adoption. 


\section{Appendix A}

To begin the option analysis of the problem, we need to be more precise about the future uncertainty surrounding electricity and investment costs. We represent the changes in NRE and RE electricity costs as the geometric Brownian motions

$$
\begin{gathered}
\mathrm{d} P_{F}=\alpha P_{F} \mathrm{~d} t+\sigma_{F} P_{F} \mathrm{~d} z \\
\mathrm{~d} P_{R}=v\left(M_{0}\right) P_{R} \mathrm{~d} t+\sigma_{R}\left(M_{0}\right) P_{R} \mathrm{~d} w, \quad K>0 \\
\mathrm{~d} P_{R}=\gamma P_{R} \mathrm{~d} t+\theta_{R} P_{R} \mathrm{~d} w, \quad K=0
\end{gathered}
$$

where $\mathrm{d} z$ and $\mathrm{d} w$ are uncorrelated increments to the Gauss-Wiener process and $\sigma_{F}$ and $\sigma_{R}$ are the cost volatility parameters. Equation 6 reflects movement in NRE electricity costs. Equation 7 reflects movements in RE electricity costs during the R\&D stage and switching period, and Equation 8 reflects movements in RE electricity costs upon completion of the RE switchover period. In Equation 7, the more R\&D spending, the faster the rate of decline in RE electricity costs over time, up to a limit, before and during the RE switchover period. This is reflected in the $v\left(M_{0}\right)$ parameter, where $M_{0}$ is the current rate of R\&D spending (see Table 2). If the marginal productivity of $R \& D$ is high enough, additional $R \& D$ spending can add value to $R E$ technologies. We add the fact that additional $R \& D$ spending decreases the rate of uncertainty as to that rate of decline; the volatility of changes in the supply cost of the most competitive RE technology is reduced by the level of current spending on $R \& D .{ }^{26}$ The reasoning here is that all uncertainty about the cost of RE technology can be resolved given enough R\&D spending. On the other hand, when there is very little R\&D spending, there is increased uncertainty about eventual deployment costs. Additional R\&D spending thus increases the expected payoff from $\mathrm{RE}$ technologies by lowering RE electricity costs, but also decreases the uncertainty surrounding that payoff, each having an opposite effect on option value. We assume that the Gauss-Wiener processes for each cost process are uncorrelated, meaning that random shocks to the cost processes that cause them to deviate from the expected trends are derived from independent

\footnotetext{
${ }^{26}$ We could also allow the rate of learning-by-doing effects, reflected in the parameter $\gamma$ in Equation A.3, to be affected by the type of technology created by a R\&D program of expenditure level $M_{0}$. Increasing $M_{0}$ would result in the installation of a "better" long-run technology (see Majd and Pindyck 1989, fn. 6).
} 
economic events. ${ }^{27}$ Under these processes, the supply cost of each form of energy can drop, but can never be zero. Zero costs therefore provide lower bounds to the processes. The geometric nature of the processes also means that unexpected deviations are permanent. That is, if there is an R\&D breakthrough that suddenly lowers the cost of producing RE electricity, we never lose that technological advance.

We take remaining switchover expenditure $K$ at any time to be uncertain, with changes in $K$ following the controlled diffusion process

$$
\mathrm{d} K=-i P_{F} \mathrm{~d} t+\beta\left[i P_{F} K\right]^{0.5} \mathrm{~d} x
$$

where, again, $i P_{F}=I$ and $\mathrm{d} x$ is an increment to a Gauss-Wiener process that is uncorrelated with the market portfolio and uncorrelated with either of the two cost processes (Schwartz and Moon 2000). ${ }^{28}$ The uncertainty in $K$ relates to technical uncertainty, whereby the number of periods in which $I$ must be spent is unknown. Costs may be greater, and the switchover period extended, if unexpended technical, legal, or legislative impediments to deployment of RE are discovered once RE switchover is initiated. Notice that if $I=0$ then $d K=0$, and there is no resolution of this technical uncertainty over the level of $K$ required to bring RE to market. ${ }^{29}$ This uncertainty is only resolved once the switchover period is underway. Any successful reduction in $K$ through spending $I$ also, by reducing the time to build, brings the payoffs closer and reduces the uncertainty over the final payoff to be received once switchover period is completed.

The term $\beta$ is a scale parameter reflecting the uncertainty surrounding $K$. If $\beta=0, K$ is certain, the usual assumption in DCF analysis. In Equation 9, the stochastic term $\beta\left[i P_{F} K\right]^{0.5} \mathrm{~d} x$ has a

\footnotetext{
${ }^{27}$ Shocks to the supply price of fossil fuel are, for example, a result of changing inventories, whereas shocks to the supply cost of renewables are related to technological uncertainties. Any correlation between the costs of RE and NRE electricity are likely to be minor, and including these correlations into the calculations greatly increases their complexity. Thus, we choose to ignore them.

${ }^{28}$ This is a controlled diffusion process because $i$ is a control variable. One might envision the level of $K$ as being dependent on and negatively related to the value of renewable energy. For now we assume $K$ is the relatively minor cost of a fixed number of "tasks" involved with bringing RE online. The cost of these tasks do not vary with the level of market penetration of RE. See Berk et al. (1998) for a model where $K$ varies with the profitability and scale of the underlying project.

${ }^{29}$ However, as we noted above, since $K$ is constant in nominal terms, there is some technical learning while waiting to invest. The fact that the risk in $K$ cannot be replicated, and so learning can only take place through capital expenditures, means that markets are incomplete.
} 
mean of zero, meaning that the expected level of $K$ is unbiased. Uncertainty decreases as $K$ decreases, reflecting learning with investment; the variance of $K$ is

$$
\sigma_{K}^{2}(K)=\left(\frac{\beta^{2}}{2-\beta^{2}}\right) K^{2}
$$

Based on data presented in Pindyck (1993), we assume $\beta=0.5$. The total switchover cost is the integral of actual investments made, which can only be known at the completion of the switchover period.

This is a compound option, sequential investment problem with technical uncertainty. ${ }^{30}$ The option is a compound option because of the time to build nature of the investment problem (Majd and Pindyck 1987, Dixit and Pindyck 1994, Chapter 10). In a discrete sense, each annual switchover expenditure, $I$, creates a new investment option on the present value of cost savings from the installed RE technology, with a diminished exercise price of $K-I$. The switchover program can be costlessly suspended, allowing the flexibility of abandoning the switchover, either temporarily or permanently.

These facets of the model merely formalized the aspects of uncertainty contained within the valuation problem. As in the DCF analysis above, the expected present value of the investment opportunity, if undertaken immediately at the maximum rate, is still as in Equation 4 above. All we have done is parameterized the nature of the future economic uncertainty in our model. Having formalized the uncertainties in the problem, we now proceed to value the portfolio of available RE technologies as a compound perpetual American call option whose value is affected by the rate of RE R\&D spending.

Let the option value of RE technologies be $\Phi\left(P_{R}, P_{F}, K\right)$. The approach to valuing $\Phi\left(P_{R}, P_{F}, K\right)$ is similar to that used in Schwartz and Moon (2000). We assume the risk in $P_{R}$ and $K$ is unsystematic, and the risk in $P_{F}$ is traded in the market. These assumptions allow us to use equilibrium arguments to derive the value of the option $\Phi\left(P_{R}, P_{F}, K\right)$. Applying Ito's Lemma to $\Phi\left(P_{R}, P_{F}, K\right)$, and assuming $\Phi$ is continuous and twice differentiable in its arguments, we have

\footnotetext{
${ }^{30}$ Pindyck (1993) proposes a model where there is also input cost uncertainty. In this case, we abstract from input cost uncertainty, as it seems to be relatively minor.
} 


$$
d \phi=\phi_{P_{R}} d P_{R}+\phi_{P_{F}} d P_{F}+\phi_{K} d K+\frac{1}{2} \phi_{P_{R} P_{R}} P_{R}^{2} \sigma_{R}^{2} d t+\frac{1}{2} \phi_{P_{F}} P_{F} P_{F}^{2} \sigma_{F}^{2} d t+\frac{1}{2} \phi_{K K} \beta^{2} i P_{F} K \mathrm{~d} t
$$

Consider an optimally managed portfolio consisting of one unit of the option and $h$ units short in a traded NRE electricity derivative such as electricity futures that spans the risk in spot electricity cost. ${ }^{31}$ Let $X$ denote the market price of this spanning asset, with

$$
\mathrm{d} X=A\left(P_{F}, t\right) X \mathrm{~d} t+B\left(P_{F}, t\right) X \mathrm{~d} z
$$

Since the spanning asset is a traded asset, its rate of drift must return the required rate for assets of this risk class. The value of the portfolio at initiation is $\pi=(\phi-h X)$, and, holding the short position constant, the portfolio's change in value over some small period $\mathrm{d} t$ is

$$
\mathrm{d} \pi=\mathrm{d}(\phi-h X)=\mathrm{d} \phi-h \mathrm{~d} X .
$$

If we choose $h=\frac{\sigma_{F} P_{F} \phi_{P_{F}}}{B X}$, the holder of the portfolio receives the capital gain

$$
\begin{aligned}
\mathrm{d} \pi=\phi_{P_{F}}\left(\alpha P_{F}-\frac{\sigma_{F} P_{F} A}{B}\right) d t+\phi_{P_{R}} \mathrm{~d} P_{R}+\phi_{K} \mathrm{~d} K+\frac{1}{2} \phi_{P_{R} P_{R}} P_{R}^{2} \sigma_{R}^{2} \mathrm{~d} t+\frac{1}{2} \phi_{P_{F} P_{F}} P_{F}^{2} \sigma_{F}^{2} \mathrm{~d} t & \\
& +\frac{1}{2} \phi_{K K} \beta^{2} i P_{F} K \mathrm{~d} t .
\end{aligned}
$$

Due to the presence of the terms $\mathrm{d} P_{R}$ and $\mathrm{d} K$, the capital gain is uncertain. The expected capital gain is

$$
\begin{aligned}
E(\mathrm{~d} \pi)=\phi_{P_{F}}\left(\alpha P_{F}-\frac{\sigma_{F} P_{F} A}{B}\right) d t+\phi_{P_{R}} v P_{R} \mathrm{~d} t-\phi_{K} i P_{F} \mathrm{~d} t & +\frac{1}{2} \phi_{P_{R} P_{R}} P_{R}^{2} \sigma_{R}^{2} \mathrm{~d} t \\
& +\frac{1}{2} \phi_{P_{F} P_{F}} P_{F}^{2} \sigma_{F}^{2} \mathrm{~d} t+\frac{1}{2} \phi_{K K} \beta^{2} i P_{F} K \mathrm{~d} t .
\end{aligned}
$$

\footnotetext{
${ }^{31}$ Electricity trading is confined to wholesale markets, either for delivery or cash settlement (Bessembinder and Lemmon 1999). We assume that the portfolio holder has access to this market, and that the risk in the wholesale market spans the risk in the retail market.
} 
While holding the portfolio, the investor incurs holding costs $m P_{F} \mathrm{~d} t$, and, when $\mathrm{d} K \neq 0$, investment costs $i P_{F} \mathrm{~d} t$. Since the portfolio only contains unsystematic risk, the expected return on holding the portfolio, which includes capital gains less side payments, is, in equilibrium, $r(\phi$ $h X) \mathrm{d} t .{ }^{32}$ Equating the expected capital gain, less the portfolio holding and investment costs, to the equilibrium expected return $r(\phi-h X) \mathrm{d} t$,

$$
\begin{array}{rl}
\phi_{P_{F}}\left(\alpha P_{F}-\frac{\sigma_{F} P_{F} A}{B}\right) d t+\phi_{P_{R}} v P_{R} \mathrm{~d} & t-\phi_{K} i P_{F} \mathrm{~d} t-m P_{F} \mathrm{~d} t-i P_{F} \mathrm{~d} t+\frac{1}{2} \phi_{P_{R} P_{R}} P_{R}^{2} \sigma_{R}^{2} \mathrm{~d} t \\
& +\frac{1}{2} \phi_{P_{F} P_{F}} P_{F}^{2} \sigma_{F}^{2} \mathrm{~d} t+\frac{1}{2} \phi_{K K} \beta^{2} i P_{F} K \mathrm{~d} t=r\left(\phi-\frac{\sigma_{F} P_{F}}{B X} \phi_{P_{F}} X\right) \mathrm{d} t .
\end{array}
$$

Simplifying,

$$
\begin{aligned}
v P_{R} \phi_{P_{R}}-i P_{F} \phi_{K}+\left(\alpha-\sigma_{F} \frac{(A-r)}{B}\right) P_{F} \phi_{P_{F}}+\frac{1}{2} \phi_{P_{R} P_{R}} P_{R}^{2} \sigma_{R}^{2} & +\frac{1}{2} \phi_{P_{F} P_{F}} P_{F}^{2} \sigma_{F}^{2} \\
& +\frac{1}{2} \phi_{K K} \beta^{2} i P_{F} K-r \phi-m P_{F}-i P_{F}=0,
\end{aligned}
$$

or equivalently, under optimal asset management,

$$
\begin{aligned}
v P_{R} \phi_{P_{R}}+\left(\alpha-\sigma_{F} \frac{(A-r)}{B}\right) P_{F} \phi_{P_{F}} & +\frac{1}{2} \phi_{P_{R} P_{R}} P_{R}^{2} \sigma_{R}^{2}+\frac{1}{2} \phi_{P_{F} P_{F}} P_{F}^{2} \sigma_{F}^{2} \\
& -r \phi-m P_{F}+\max _{0 \leq i \leq i_{\max }}\left\{i\left(\frac{1}{2} \phi_{K K} \beta^{2} P_{F} K-P_{F} \phi_{K}-P_{F}\right), 0\right\}=0
\end{aligned}
$$

The term $\left(\alpha-\sigma_{F} \frac{(A-r)}{B}\right)$ is the risk-adjusted rate of drift of the cost of NRE electricity, with the risk adjustment coming from observations of the return characteristics for the spanning asset. Note that NPV Equation 3, under equivalent risk-neutral valuation, is a solution to Equation 14 when $\sigma_{F}=\sigma_{R}=\beta=0 . .^{33}$

\footnotetext{
${ }^{32}$ Even though markets are incomplete in our model, it is still possible for the development of this project to leave the equilibrium pricing kernel unaffected (Childs et al. 1998).

${ }^{33}$ See Dixit and Pindyck (1994), pp. 121-125, for a description of risk-neutral valuation.
} 
This is a problem with three state variables, the cost of RE electricity, the cost of NRE electricity, and the remaining investment required to complete the switchover. Given a rate of $\mathrm{R} \& \mathrm{D}$ spending response, $m$, there is one control variable, the rate of switchover response, $i$, which can vary from 0 to $i_{\max }$. Since Equations 13 and 14 are linear in $i$, the optimal level of deployment will be zero if $\left(\frac{1}{2} \phi_{K K} \beta^{2} K-\phi_{K}-1<0\right)$ or $i_{\max }$ if $\left(\frac{1}{2} \phi_{K K} \beta^{2} K-\phi_{K}-1 \geq 0\right){ }^{34}$

Thus, when it is optimal to initiate RE deployment, the value of the option is represented by the partial differential equation

$$
\begin{aligned}
v P_{R} \phi_{P_{R}}-i_{\max } P_{F} \phi_{K}+\left(\alpha-\sigma_{F} \frac{(A-r)}{B}\right) P_{F} \phi_{P_{F}}+\frac{1}{2} \phi_{P_{R} P_{R}} P_{R}^{2} \sigma_{R}^{2}+\frac{1}{2} \phi_{P_{F} P_{F}} P_{F}^{2} \sigma_{F}^{2} \\
+\frac{1}{2} \phi_{K K} \beta^{2} i_{\max } P_{F} K-r \phi-m P_{F}-i_{\max } P_{F}=0
\end{aligned}
$$

When the option is being held and the deployment response rate is zero, the relevant differential equation is

$$
v(m) P_{R} \phi_{P_{R}}+\left(\alpha-\sigma_{F} \frac{(A-r)}{B}\right) P_{F} \phi_{P_{F}}+\frac{1}{2} \phi_{P_{R} P_{R}} P_{R}^{2} \sigma_{R}^{2}+\frac{1}{2} \phi_{P_{F}} P_{F} P_{F}^{2} \sigma_{F}^{2}-r \phi-m P_{F}=0
$$

The value of the RE technologies is indicated by the solution to Equations 15 and 16 given the appropriate boundary conditions. The free boundary is $\left(P^{*}{ }_{F}\left(P_{R}, K\right)\right)$.

This is a stochastic problem in three variables. It is helpful to simplify the problem using its natural homogeneity. Doubling the current values of $P_{R}, P_{F}$ and $K$ merely doubles the expected value of RE technology installations and the expected cost of investing in RE installation. As such, the valuation problem is linear homogenous, and we can again, as in the DCF analysis above, convert the problem into one of cost ratios by using the cost of NRE electricity as the numeraire. We can then write

$$
\Phi\left(P_{R}, P_{F}, K\right)=P_{F} N(p, k)
$$

\footnotetext{
${ }^{34}$ Note that $P_{F}>0$.
} 
where again $p=P_{R} / P_{F}$ and $k=K / P_{F}$. The value of the function $N$ is now to be determined, which, when multiplied by the current cost of NRE-generated electricity, will give the option value of RE technologies program. Differentiating $\Phi\left(P_{R}, P_{F}, K\right)$ and $N(p, k)$ gives

$$
\begin{gathered}
\phi_{P_{F}}\left(P_{R}, P_{F}, K\right)=P_{F} N_{p}(p, k)\left(-\frac{P_{R}}{P_{F}^{2}}\right)+P_{F} N_{k}(p, k)\left(-\frac{K}{P_{F}^{2}}\right)+N(p, k) \\
=N(p, k)-p N_{p}(p, k)-k N_{k}(p, k) \\
\phi_{P_{F} P_{F}}\left(P_{R}, P_{F}, K\right)= \\
N_{p}(p, k)\left(-\frac{P_{R}}{P_{F}^{2}}\right)+N_{k}(p, k)\left(-\frac{K}{P_{F}^{2}}\right)-p N_{p p}(p, k)\left(-\frac{P_{R}}{P_{F}^{2}}\right)-p N_{p k}(p, k)\left(-\frac{K}{P_{F}^{2}}\right) \\
-N_{p}(p, k)\left(-\frac{P_{R}}{P_{F}^{2}}\right)-k N_{k p}(p, k)\left(-\frac{P_{R}}{P_{F}^{2}}\right)-k N_{k k}(p, k)\left(-\frac{K}{P_{F}^{2}}\right)-N_{k}(p, k)\left(-\frac{K}{P_{F}^{2}}\right) \\
=\left(p^{2} N_{p p}(p, k)+2 p k N_{p k}(p, k)+k^{2} N_{k k}(p, k)\right)\left(\frac{1}{P_{F}}\right)
\end{gathered}
$$

$$
\begin{gathered}
\phi_{P_{R}}\left(P_{R}, P_{F}, K\right)=P_{F} N_{p}(p, k)\left(\frac{1}{P_{F}}\right)=N_{p}(p, k) \\
\phi_{P_{R} P_{R}}\left(P_{R}, P_{F}, K\right)=N_{p p}(p, k)\left(\frac{1}{P_{F}}\right) \\
\phi_{K}\left(P_{R}, P_{F}, K\right)=P_{F} N_{k}(p, k)\left(\frac{1}{P_{F}}\right)=N_{k}(p, k) \\
\phi_{K K}\left(P_{R}, P_{F}, K\right)=N_{k k}(p, k)\left(\frac{1}{P_{F}}\right)
\end{gathered}
$$

Substituting conditions (18) through (23) into (15) and (16) and simplifying gives the related partial differential equations when $P_{F}$ is the numeraire,

$$
\begin{gathered}
\frac{1}{2}\left(\sigma_{R}^{2}+\sigma_{F}^{2}\right) p^{2} N_{p p}(p, k)+\frac{1}{2}\left(k^{2} \sigma_{F}^{2}+\beta^{2} i_{\max } k\right) N_{k k}(p, k)+p k \sigma_{F}^{2} N_{p k}(p, k)-\left(i_{\max }+\psi k\right) N_{k}(p, k) \\
+(v-\psi) p N_{p}(p, k)+(\psi-r) N(p, k)-m-i_{\max }=0
\end{gathered}
$$

and 


$$
\begin{aligned}
\frac{1}{2}\left(\sigma_{R}^{2}+\sigma_{F}^{2}\right) p^{2} n_{p p}(p, k)+\frac{1}{2} k^{2} \sigma_{F}^{2} n_{k k}( & p, k)+p k \sigma_{F}^{2} n_{p k}(p, k)-\psi k n_{k}(p, k) \\
& +(v-\psi) p n_{p}(p, k)+(\psi-r) n(p, k)-m=0
\end{aligned}
$$

where $\psi=\alpha-\sigma_{F} \frac{(A-r)}{B}$. Once again, we note that the NPV Equation 4, under equivalent riskneutral valuation, is a solution to Equation 24.

Unfortunately, we cannot observe the spanning asset's performance since this information is not publicly available so we cannot estimate $A$ or $B$. From the analysis of Bessembinder and Lemmon (1999), we tentatively assume that the spanning asset has a zero price of risk, making $A$ $=r$, and $\psi=\alpha$.

We now have two partial differential equations, 24 and 25, the first applying to the $(p, k)$ region in which investment in RE market conditioning is taking place at rate $i_{\max }$, and the second applying to the region where no switchover is taking place. Equations 24 and 25 can be solved for $N$ and $n$, and thus for $\phi$, given the problem's boundary conditions. The first boundary is the value of the option at $k=0$, when the switchover is complete. The equations for calculating the option value of the program at $k=0$ are

$$
\begin{gathered}
n(p)=E[N P V(p)]=\frac{q}{(\hat{\alpha}-\alpha)}\left[1+\frac{1}{(\hat{\alpha}-\alpha)}\right]-\frac{p q}{(\hat{\gamma}-\gamma)}\left[1+\frac{1}{(\hat{\gamma}-\gamma)}\right], p>p^{*} \\
\frac{1}{2}\left(\sigma_{R}^{2}+\sigma_{F}^{2}\right) p^{2} n_{p p}(p)+(v-\alpha) p n_{p}(p)+(\alpha-r) n(p)-m=0, p_{a b}^{*}<p<p^{*} \\
n(p)=0, p<p_{a b}^{*}
\end{gathered}
$$

where $p^{*}$ is the relative cost level at which RE begins meeting incremental demand and $p_{a b}^{*}$ is the relative cost level at which RE technologies are abandoned. There are also value-matching and smooth pasting conditions at $p^{*}{ }_{a b}$ and $p^{*}$. Equation 26 states that once switchover is complete, the value of the RE technologies is the expected NPV of cost savings given that it is optimal to turn on the installed RE technologies. Equation 27 is the value of RE technologies when it is optimal to wait before turning them on. Equation 28 is the value of abandoned RE technologies. Abandonment may be optimal when waiting incurs ongoing RE R\&D costs. 
When $k>0$ Equations 24 and 25 are solved using the $k=0$ option value and the additional boundary conditions,

$$
\begin{gathered}
n\left(p^{*}{ }_{\mathrm{ab}}, k\right)=0 \\
n_{p}\left(p^{*}{ }_{\mathrm{ab}}, k\right)=0 \\
N\left(p^{*}, k\right)=n\left(p^{*}, k\right) \\
N_{p}\left(p^{*}, k\right)=n_{p}\left(p^{*}, k\right) \\
\frac{1}{2} N_{k k}\left(p^{*}, k\right) \beta^{2} k-N_{k}\left(p^{*}, k\right)=\frac{1}{2} n_{k k}\left(p^{*}, k\right) \beta^{2} k-n_{k}\left(p^{*}, k\right)=1
\end{gathered}
$$

Boundary Equations 29 and 30 allow for the costless abandonment of the program, should the option value, in the light of the holding costs $m$, become negative, where $p^{*}{ }_{\mathrm{ab}}(k)$ is the abandonment boundary. Equation 30 is the "smooth pasting" efficiency condition at this boundary. Equations 31 and 32 are the continuity and smooth pasting conditions at the $\left(p^{*}, k\right)$ boundary between switchover and no switchover. In these boundary conditions, we assume that the switchover program can be suspended and recommenced at no cost. Equation 33 is the investment optimality condition at the free boundary (Milne and Whalley 2000).

A numerical method must be employed to produce the values of $N(p, k), n(p, k)$ and the free boundaries $p^{*}(k)$ and $p^{*}{ }_{\mathrm{ab}}(k)$ given specified parameter values. From this, the actual current option value $\Phi\left(P_{R}, P_{F}, K\right)$ can be recovered by multiplying $N(p, k)$ or $n(p, k)$ by the current value of $P_{F}$. Within the numerical procedure, a finite difference procedure is used to discretize Equations 24 and 25. The two second-order derivative terms in these equations are discretized using a standard three-point stencil, the second-order mixed derivative term is approximated by a fourpoint stencil scheme at each rectangular grid point. The two first-order terms are treated using the standard up-winding finite difference scheme that ensures a stable and accurate approximation for the governing equations. The discretized equations are then solved iteratively 
by a method that is similar to the Schwarz domain decomposition technique that has been well studied for elliptic problems and variational inequalities. The domain decomposition method is a very efficient technique for free boundary value problems such as the valuation of American options. 


\section{References}

American Wind Energy Association (AWEA) (2002), Wind Energy Outlook 2002, Washington, D.C.

Arthur, W. Brian (1989), Competing technologies, increasing returns, and lock-in by historical events, Economic Journal 99, 116-131.

Awerbuch, Shimon, and William Deehan (1995), Do consumers discount the future correctly? A marketbased valuation of residential fuel switching, Energy Policy 1, 57-69.

Ball, Ben and Richard Tabors (1990), Energy Aftermath, Harvard Business School Press, Boston, MA.

Berk, Jonathan B., Richard C. Green, and Vasant Naik (1998), Valuation and return dynamics of new ventures. Working Paper, University of California, Berkeley, Carnegie Mellon University, and University of British Columbia.

Bessembinder, Hendrik, and Michael L. Lemmon (1999), Equilibrium pricing and optimal hedging in electricity forward markets, Working paper, Emory University and Arizona State University.

Bradley, Robert L. (1997), Renewable Energy: Not Cheap, Not "Green", The Cato Institute, Cato Policy Analysis No. 280, Washington, D.C.

Childs, Paul D., and Alexander J. Triantis (1999), Dynamic R\&D investment policies, Management Science 45, 1359-1377.

Childs, Paul D., Steven H. Ott, and Alexander J. Triantis (1998), Capital budgeting for interrelated projects: a real options approach, Journal of Financial and Quantitative Analysis 33, 305-334.

Cohen, Linda and Roger Noll (1991), The Technology Pork Barrel, The Brookings Institution, Washington, D.C.

Department of Energy (DOE) (1998), Comprehensive National Energy Strategy, DOE/S-0124, U.S. Department of Energy, Washington, D.C.

Dixit, Avinash K., and Robert S. Pindyck (1994), Investment Under Uncertainty. Princeton: Princeton University Press.

Dooley, J.J. (1998), Unintended consequences: Energy R\&D in a deregulated energy market, Energy Policy, 26, 547-555.

Electric Power Research Institute (EPRI) (1997), Renewable Energy Technology Characterizations, EPRI-TR-109496, Pleasant Hill, CA.

Elliott, D.L., and M.N. Schwartz (1993), Wind energy potential in the United States, Pacific Northwest Laboratory PNL-SA-23109, Richland, WA.

Energy Efficiency and Renewable Energy, Office of (EERE) (2000), Clean Energy for the $21^{\text {st }}$ Century, DOE/GO-102000-0956, U.S. Department of Energy, Washington, D.C. 
Energy Information Administration (EIA) (2001), Annual Energy Outlook 2002, DOE/EIA-0383(2002), U.S. Department of Energy, Washington, D.C.

Energy Information Administration (EIA) (2000a), Annual Energy Review, DOE/EIA-0384(99), U.S. Department of Energy, Washington, D.C.

Energy Information Administration (EIA) (2000b), Historical Natural Gas Annual: 1930 Through 1999, DOE/EIA-E-0110(99), U.S. Department of Energy, Washington, D.C.

Energy Information Administration (EIA) (2000c), Renewable Energy Annual, DOE/EIA-0603(99), U.S. Department of Energy, Washington, D.C.

Energy Information Administration (EIA) (1999), Annual Energy Outlook 2000, DOE/EIA-0383(2000), U.S. Department of Energy, Washington, D.C.

Energy Information Administration (EIA) (1993), Historical Monthly Energy Review, DOE/EIA0035(73-92), U.S. Department of Energy, Washington, D.C.

Federal Energy Regulatory Commission (FERC) (1997), Form One Database 1994-1996, U.S. Department of Energy, Washington D.C.

General Accounting Office (GAO) (1996), Federal Research: Changes in Electricity-Related R\&D Funding, U.S. General Accounting Office, Washington, D.C.

Huchzermeier, Arndt, and Christoph H. Loch (2001) Project Management Under Risk: Using the Real Options Approach to Evaluate Flexibility in R\&D, Management Science, 47, 1, 85-101.

Kumaraswamy, Arun (1997), An empirical investigation of a real options perspective on R\&D. Working Paper, Rutgers University.

Laughton, David G., S. Frimpong, and J. M. Whiting (1993), The costs and benefits of project-level commercial research, Working Paper 2-93, University of Alberta.

Majd, Saman, and Robert S. Pindyck (1987), Time to build, option value, and investment decisions, Journal of Financial Economics 18, 7-27.

Majd, Saman, and Robert S. Pindyck (1989), The learning curve and optimal production under uncertainty, RAND Journal of Economics 20, 331-343.

Management Information Services Inc. (MISI) (1998) Federal Incentives for Energy Industries, Washington, DC.

Margolis, Robert M., and Daniel M. Kammen (1999), Evidence of under-investment in energy R\&D in the United States and the impact of Federal Policy, Energy Policy, 27, 575-584.

McVeigh, James, Dallas Burtraw, Joel Darmstadter, and Karen Palmer (2000), Winner, loser, or innocent victim? Has renewable energy performed as expected?, Solar Energy, 68, 3, 237-255.

Milne, Alistair, and A. Elizabeth Whalley (2000), 'Time to build, option value and investment decisions': a comment, Journal of Financial Economics 56, 325-332. 
National Petroleum Council (NPC) (1999), Meeting the Challenges of the Nation's Growing Natural Gas Demand, NRC, Washington, D.C.

Office of Technology Assessment (OTA) (1995), Renewing Our Energy Future, OTA-ETI-614, U.S. Congress, OTA, Washington, D.C.

Ott, Steven H., and Howard E. Thompson (1996), Uncertain outlays in time-to-build problems, Managerial and Decision Economics 17, 1-16.

Pindyck, Robert S. (1993), Investments of uncertain cost, Journal of Financial Economics 34, 53-76.

President's Committee of Advisors on Science and Technology (PCAST) (1997), Federal Energy Research and Development for the Challenges of the $21^{\text {st }}$ Century, Washington, D.C.

Read, J. A. (1995), Option pricing for project evaluation: an introduction, EPRI Research Report TR104755.

Roberts, Kevin, and Martin L. Weitzman (1981), Funding criteria for research, development, and exploration projects, Econometrica 49, 1261-1288.

Sagar, Ambuj D. (2000), Evidence of under-investment in energy R\&D in the United States and the impact of Federal Policy: A comment on Margolis and Kammen, Energy Policy, 28, 651-654.

Schock, Robert N., William Fulkerson, Merwin L. Brown, Robert L. San Martin, David L. Greene, and Jae Edmonds (1999), How much is energy R\&D worth as insurance?, working paper, Joint Institute for Energy and Environment, University of Tennessee.

Schwartz, Eduardo S., and Mark Moon (2000), Evaluating research and development investments, in Project Flexibility, Agency, and Competition, Michael J. Brennan and Lenos Trigeorgis, eds. New York: Oxford University Press, 85-106.

Smit, Han T., and Lenos Trigeorgis (1997), Flexibility and competitive R\&D strategies. Working Paper, Erasmus University and Columbia University.

Taylor, Jerry, and Peter Van Doren (2002), Evaluating the Case for Renewable Energy: Is Government Support Warranted?, The Cato Institute, Cato Policy Analysis No. 422, Washington, D.C.

Taylor, Jerry (1999), Energy Efficiency: No Silver Bullet for Global Warming, The Cato Institute, Cato Policy Analysis No. 356, Washington, D.C.

Willner, Ram (1995), Valuing start-up venture growth options, in Real Options in Capital Investment: Models, Strategies, and Applications, Lenos Trigeorgis, ed. Westport, Conn: Praeger, 221-239. 


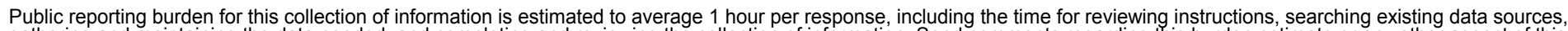

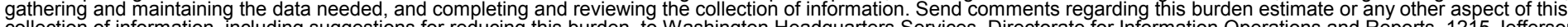
this burden, to Washington Headquarters Services, Directorate for Information Operations and Reports, 1215 Jefferson Davis Highway, Suite 1204, Arlington, VA 22202-4302, and to the Office of Management and Budget, Paperwork Reduction Project (0704-0188), Washington, DC 20503.
1. AGENCY USE ONLY (Leave blank)
2. REPORT DATE
February 2003
3. REPORT TYPE AND DATES COVERED
Technical Report - Analysis
4. TITLE AND SUBTITLE Optimizing the Level of Renewable Electric R\&D Expenditures Using Real Options Analysis

5. FUNDING NUMBERS

TA: AS65.2010

6. AUTHOR(S)

G. Davis and B. Owens

7. PERFORMING ORGANIZATION NAME(S) AND ADDRESS(ES)

National Renewable Energy Laboratory

1617 Cole Blvd.

Golden, CO 80401-3393

8. PERFORIMING ORGANIZATION REPORT NUMBER

NREL/TP-620-31221

9. SPONSORING/MONITORING AGENCY NAME(S) AND ADDRESS(ES)

10. SPONSORING/MONITORING AGENCY REPORT NUMBER

11. SUPPLEMENTARY NOTES

12a. DISTRIBUTION/AVAILABILITY STATEMENT

National Technical Information Service

12b. DISTRIBUTION CODE

U.S. Department of Commerce

5285 Port Royal Road

Springfield, VA 22161

13. ABSTRACT (Maximum 200 words)

One of the primary objectives of the United States' federal non-hydro renewable electric R\&D program is to promote the development of technologies that have the potential to provide consumers with stable and secure energy supplies. In order to quantify the benefits provided by continued federal renewable electric R\&D, this paper uses "real option" pricing techniques to estimate the value of renewable electric technologies in the face of uncertain fossil fuel prices. Within the real options analysis framework, the current value of expected future supply from renewable electric technologies, net of federal R\&D expenditures, is estimated to be $\$ 30.6$ billion. Of this value, $86 \%$ can be attributed to past federal R\&D efforts, and $14 \%$ can be attributed to future federal R\&D efforts, assuming continued federal R\&D funding at $\$ 300$ million/year. In addition, real options analysis shows that the value of renewable electric technologies increases as current and future R\&D funding levels increase. This indicates that the current level of federal renewable electric R\&D funding is sub-optimal low.

14. SUBJECT TERMS

real options analysis, renewable energy, renewable electric R\&D, market value, discounted cash flow model, real options model, R\&D expenditures, Graham Davis, Brandon Owens

17. SECURITY CLASSIFICATION OF REPORT

Unclassified
18. SECURITY CLASSIFICATION OF THIS PAGE Unclassified
19. SECURITY CLASSIFICATION OF ABSTRACT Unclassified
15. NUMBER OF PAGES

16. PRICE CODE

20. LIMITATION OF ABSTRACT

UL 